\title{
EL CONTEXTO DEL ARTE PARIETAL. LA TECNOLOGIA DE LOS ARTISTAS EN LA CUEVA DE TITO BUSTILLO (ASTURIAS)
}

\author{
POR \\ ALFONSO MOURE ROMANILLO (") \\ MANUEL R. GONZALEZ MORALES (**)
}

\begin{abstract}
RESUMEN El trabajo coincide parcialmente con la comunicación presentada al «Colloque International d'Art Parietal Paléolithique" celebrado en Perigueux-Le Thot, en diciembre de 1984. Se analizan las respuestas tecnológicas contenidas en un área de decoración de la cueva de Tito Bustillo (Asturias), así como las actividades en áreas de estancia relacionadas con la preparación y ejecución del arte parietal.
\end{abstract}

\begin{abstract}
This study overlaps in part with a communication presented to the "Colloque International d'Art Parietal Paléolithique," held at Perigueux-Le Thot in december 1984. The technological responses contained in a decorated zone of the cave of Tito Bustillo are analyzed, as well as the activities carried out on living floors related to the preparation and completion of the parietal art.
\end{abstract}

Palabras clave: Arte rupestre paleolítico. Tecnología del arte. Magdaleniense.

El arte rupestre es un aspecto del comportamiento cultural de las poblaciones paleolíticas, relacionado con la práctica totalidad de las actividades realizadas en los espacios subterráneos, y consecuentemente, con los vestigios conservados de las mismas. Una imaginaria estación que haya sido utilizada como asentamiento de manera ocasional o relativamente prolongada puede permitir. conocer una importante cantidad de actuaciones relacionadas de forma directa o indirecta con la ejecución del arte parietal: los desplazamientos por su interior, la preparación y ejecución de las obras de arte, su iluminación, el acceso a los paneles, la propia utilización de la cueva como asentamiento y las actividades ejecutadas en el mismo.

Sin embargo, pocas veces ha sido posible establecer una conexión inmediata entre vestigios mobiliares y figuras parietales en áreas de decoración. Muchas veces la ausencia de datos se debe a procesos de degradación natural o a su propia inexistencia, mientras que en otras han pasado desapercibidos, o han sido destruidos o no valorados científicamente como consecuencia de actuaciones incontroladas o falta de una auténtica planificación científica. El caso de la cueva de Tito

(") Museo Arqueológico Nacional. Madrid.

(“) Universidad de Cantabria. Santander. 
Bustillo (Asturias) puede considerarse ciertamente excepcional, al menos en lo que concierne a la conservación de un pequeño nivel arqueológico al pie del panel principal de las pinturas polícromas.

Esta comunicación pretende dar a conocer algunos resultados obtenidos en el área de decoración de la cueva de Tito Bustillo, dentro del proyecto de investigación actualmente en curso. Para ello se parte de un esquema global de la distribución y repartición del espacio subterráneo, que posteriormente intentaremos ejemplificar con esa cueva cantábrica.

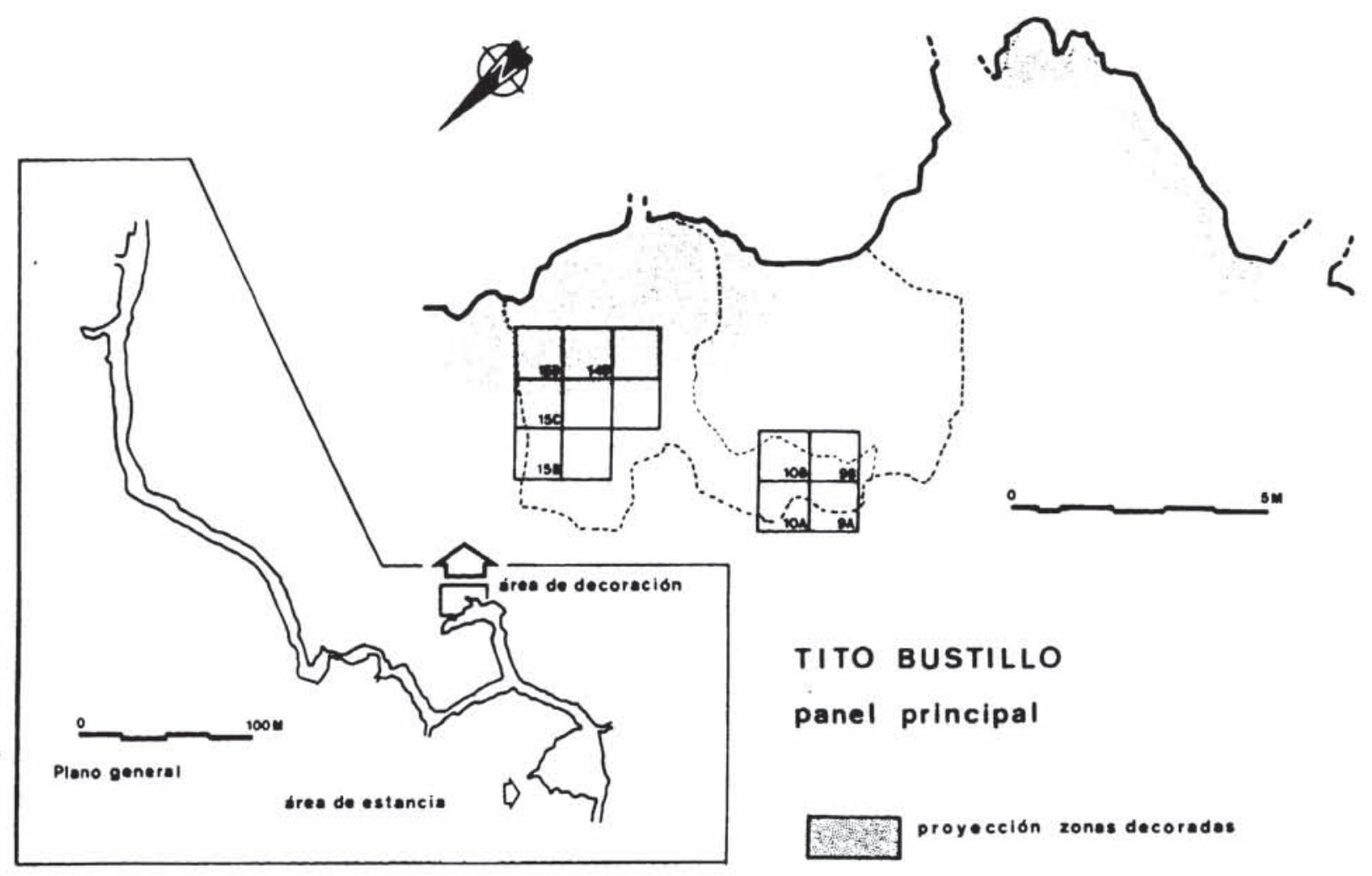

Fig. 1.- Plano de la cueva de Tito Bustillo y detalle del área de decoración.

\section{ORGANIZACION DEL ESPACIO SUBTERRANEO}

Cuando se habla de cuevas paleolíticas tiende a pensarse en dos tipos de manifestaciones en otras tantas zonas o áreas: las áreas de estancia y los paneles o sectores decorados, que pueden coincidir topográficamente o no. En este último caso, entre ambas se pueden encontrar una serie de vestigios de tránsito o acceso que representan el desplazamiento humano de una zona a otra o, simplemente, eventuales exploraciones de finalidad desconocida, por el ambiente subterráneo. Utilizando un lenguaje ya consagrado, entre otras en la obra de Rouzaud (1978), podemos diferenciar tres grandes ámbitos: áreas o espacios de estancia, de tránsito y de decoración. 


\subsection{Las áreas de estancia}

Normalmente, la idea de área de estancia se asocia a un asentamiento más que ocasional, relativamente prolongado (quizá estacional o, raramente, semipermanente) y situado por lo general en zonas exteriores o inmediatas a la entrada de la cueva. La duración del asentamiento y, en su caso, su funcionalidad especifica dependen, fundamentalmente, de las condiciones naturales del yacimiento y del territorio, pero, en todo caso, se salen ampliamente del tema objeto de esta comunicación. En la obra ya citada de F. Rouzaud (1978: 10) se distinguen tres posibles ubicaciones de acuerdo con el carácter exterior o más o menos profundo de la posición exacta de estas áreas de estancia: zonas de luz de dia, de penumbra o de oscuridad total. En cualquiera de estas situaciones, puede coincidir o no con las áreas decoradas, lo que implicaría aludir a paneles o "santuarios" exteriores o, en mayor o menor grado, profundos.

Los materiales arqueológicos y paleontológicos presentes en las áreas de estancia en la mayor parte de las casos, son representativos de actividades muy diversificadas, cuya importancia relativa está en función del tipo de asentamiento, época del año (estacionalidad) o de la propia variabilidad interna del yacimiento. Simplificando enormemente la cuestión, podría hablarse de cuatro grandes grupos de actividades representadas en los restos de ocupación: actividades de subsistencia (restos de cocina, hogares, etc.), actividades relacionadas con la tecnología de la piedra o del hueso, fabricación de objetos de arte mueble, y preparación de materiales o instrumentos relacionados con la ejecución del arte parietal. A todas ellas habría que añadir no sólo las representadas por una larga serie de objetos o restos cuya función resulta imposible por ahora de establecer, sino también todas las relacionadas con materiales perecederos, que no se conservan o sólo pueden ser estudiadas a través de evidencias latentes. Ocasionalmente, algunas estructuras difíciles de interpretar han sido relacionadas con actividades de tipo ritual, como se ha apuntado que puede ser el caso de El Juyo (González Echagaray y Freeman, 1981) o Erralla (Altuna, Baldeón y Mariezkurrena, 1984), aunque al menos en el primero de estos yacimientos tal vez algunos de los elementos no explicados pueden relacionarse con la tecnología del asta.

Las actividades de subsistencia parece que de alguna manera son las que mejor definen un área de asentamiento, aunque su análisis se aleja del objeto de este texto. Por el contrario, no siempre en estos asentamientos se realizan todas las actividades relacionadas con la tecnología de la piedra y del hueso. La extracción y talla de material lítico parece más bien propia de los yacimientos clasificables en la categoría de taller, mientras que no siempre es posible detectar la transformación "in situ" de productos de talla en útiles. En varios yacimientos cantábricos se ha podido documentar el almacenamiento de material óseo, y específicamente de asta de ciervo, para la fabricación de utensilios. Parece claro que para estas actividades fueron recolectadas astas provenientes de la muda estacional, pero, obviamente, también fueron utilizadas las procedentes de animales capturados. Los ejemplos de ambas situaciones son relativamente numerosos. En yacimientos como El Juyo o Rascaño (Cantabria) (González Echegaray y Barandiarán Maestu, 1981) aparecen astas que conservan la roseta por la que se produce la caída anual. En otros casos, los restos de cráneos de cérvido con el arranque de sus defensas intacto demuestran que fueron abatidos por o para su aprovechamiento total. Objetos de arte mueble bastante conocidos, como el «bastón de mando" de la cueva de Tito Bustillo, está claro que fueron realizados a partir de una cuerna de animal capturado, pues la superficie trabajada y decorada implica tanto la rama principal como el tramo situado entre la roseta y el cráneo (Moure-Romanillo, 1974: 848).

También se encuentran frecuentemente documentados restos de extracción de varillas corticales de asta por el procedimiento de las estrías o ranuras paralelas (Mons, 1972; Newcomer, 1977: 294 295) en varios yacimientos cantábricos, como Rascaño (González Echegaray y Barandiarán Maestu, 1981: 152), La Paloma o la propia cueva de Tito Bustillo. No faltan puntualmente ejemplos de utensilios de hueso o asta en proceso de fabricación, como una espátula de Tito Bustillo (Moure Romanillo, 1982 a), restos tecnológicos de extracción de agujas, caninos de ciervo grabados con la preparación previa al taladro del orificio de suspensión, o incluso azagayas y varillas con la punta o el bisel apenas iniciados. 
La casi totalidad de los objetos de arte mueble aparecen también en las áreas de asentamiento. Dado que un elevado porcentaje procede de excavaciones antiguas, resulta sumamente difícil hacer apreciaciones acerca de su localización exacta dentro de la superficie excavada. No obstante, determinados tipos de soportes y/o de objetos, aparecen en emplazamientos, concentraciones o estructuras intencionales y no siempre fáciles de interpretar. Destaca el caso de las plaquetas de piedra - decoradas o no- que se localizan en zonas muy delimitadas de los yacimientos o incluso formando auténticos pavimentos o empedrados, como es el caso de Enlène (Bégouén y Clottes, 1983), Tito Bustillo (Moure Romanillo, 1982 b: 5-6) o Urtiaga (González Sainz, 1984) en yacimientos en cuevas, aunque el fenómeno también está representado en lugares al aire libre como Gönnersdorf (Bosinski y Fischer, 1973). Con independencia de su posición dentro de la estructura de habitat, o de los procesos de ejecución, utilización del espacio, relación temas-soportes, etc., en el contexto del arte paleolítico, uno de los aspectos más tratados y controvertidos ha sido el de las relaciones estilisticas entre arte rupestre y arte mueble.

Posiblemente este último aspecto deba ser analizado entre las actividades de área de asentamiento relacionadas, aunque sea de manera indirecta, con el arte parietal. Además de los paralelos, ciertamente evidentes, en técnicas, temas y convencionalismos entre figuraciones mobiliares y figuraciones rupestres, algunos autores han interpretado que las representaciones mobiliares, especialmente las situadas sobre soportes planos, han servido como "modelos" o esquemas previos a su ejecución sobre las paredes de las cuevas (Obermaier, 1925: 267; Almagro Basch, 1976: 71-74). Las coincidencias en estilo y convencionalismos entre ambos tipos de manifestaciones artísticas en un mismo yacimiento ya han sido observadas en Altamira (Breuil y Obermaier, 1935: 93-113), El Castillo (Almagro Basch, 1976) y Tito Bustillo (Balbín Behrmann y Moure Romanillo, 1982 a: 89-90; Moure Romanillo, $1982 a$ y b). La propia utilización del espacio disponible en plaquetas de piedra o de hueso estudiada por Barandiarán Maestu (1984: 126-140), Delporte y Mons (1977) y González Sainz (1984) evoca claramente el empleo del campo manual en los paneles decorados. Por otra parte, la dispersión geográfica de objetos muebles muy similares o casi idénticos en un área

\section{AREAS DE ESTANCIA}

1. Actividades de subsistencia

2. Tecnologías:

- Trabajo de la piedra, del hueso o del asta

- Arte mobiliar

4. Otras actividades

3. Actividades relacionadas con el arte parietal

AREAS DE DECORACION

1. Acceso a los paneles

2. lluminación

3. Preparación kin situn del material

- Colorantes

- Material lítico para el grabado

4. Sistemas de aplicación - Tipos de colorantes

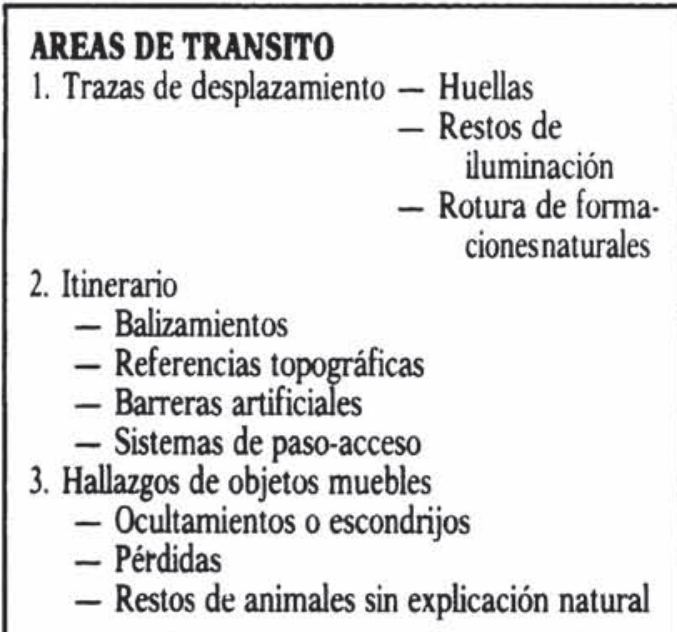

- Depósitos de pintura

5. Otros testimonios

- Material óseo

- Estructuras artificiales

- Industria lítica u ósea 
limitada - como los omóplatos tipo Castillo- coincide con la de ciertos motivos o convenciones presentes en arte parietal.

Dentro de estas actividades relacionadas con el arte rupestre, sin duda los testimonios más significativos proceden de los propios materiales de preparacion, de los colorantes ya elaborados y del material litico eventualmente empleado para el grabado.

En un buen número de áreas de ocupación son frecuentes los hallazgos de materiales colorantes en estado bruto. Los colores rojos proceden de hematites, variedad terrosa de oligisto, comúnmente conocida como "ocre rojom que se presenta en mavor o menor grado asociada a arcillas. El amarillo es variedad terrosa y amarillenta de limonita (sesquióxido hidratado de hierro) llamada también, simplemente, ocre. La "pirolusita" es una forma natural de bióxido de manganeso con gran capacidad de pigmentación negra, y la coloración blanca proviene del caolin o arcilla. Algunos fragmentos comportan estrías procedentes de su tratamiento y preparación, presentando varias caras facetadas que le dan un aspecto poliédrico, por lo que a veces han recibido el nombre de "lápices" o "tizas" (Lám. II, 2). Resultan especialmente ilustrativos, en cuanto a tipo de colorantes brutos o con huellas de utilización y a los procesos de alteración que pueden intervenir en los mismos, los estudios realizados sobre materiales de Lascaux, por Glory (1958) y Couraud y Laming-Emperaire (1970), y los de San Juan (1985) sobre varios yacimientos de Cantabria. Los instrumentos más frecuentemente relacionados con la preparación de los colorantes reciben el nombre de "morteros», "machacadores" y "yunques", unas veces por simple reflejo de la terminología al uso en tecnología de la piedra y, otras por estudios de tipo funcional, pero siempre con una acentuada dosis de subjetivismo. En todo caso suelen identificarse con relativa frecuencia bloques o cantos rodados con huellas de raspado o percusión y con restos de los materiales colorantes antes mencionados (Laming-Emperaire, 1964: 110). En el Magdaleniense Superior de la cueva de Tito Bustillo han sido clasificados como machacadores de ocre algunos cantos aplanados con huellas de raspado en ambas caras y de percusión en los bordes (Moure Romanillo, 1975: 27, lám. 22.1.) (Fig. 2). C. Perles señala también la utilización del fuego para la preparación y transformación del ocre. Determinadas tonalidades proceden de someter este material a temperaturas elevadas. Por ejemplo, el ocre rojo puede derivar de la combustión del ocre amarillo a temperaturas en torno a 250 grados centígrados (Perlés, 1977: 117).

Hay también evidencias ciertas de la existencia en las áreas de asentamiento de auténtica pintura, es decir, el polvo de color ya mezclado con algún tipo de aglutinante. Con frecuencia se presenta en forma de manchas intercaladas en los estratos, lo que no siempre permite discernir si pueden proceder o no de procesos tecnológicos o son consecuencia del azar. En otros casos puntuales su disposición intencional es evidente: sobre bloques, yunques, "paletas" o recipientes naturales. Entre los primeros son especialmente relevantes dos ejemplos cantábricos, el de la Galería A de la cueva de La Pasiega (Puente Viesgo, Cantabria), posiblemente dejado «in situ" sobre una cornisa natural en un galería intensamente decorada, o el de la capa $1 a$ de la cueva de Tito Bustillo (Ribadesella, Asturias), descubierto en el curso de la excavación sistemática y asociado a materiales del Magdaleniense con arpones (Moure Romanillo, 1975: 27). Las llamadas "paletas" son obviamente objetos de menor tamaño y superficie generalmente aplanada, como las piezas de caliza y esquisto de Lascaux (Delluc, 1979), o una plaqueta con colorante y huellas de utilización (oligisto con arenisca) de Tito Bustillo. Entre los recipientes con colorante más mencionados en la literatura científica, ya desde los tiempos del descubrimiento de Altamira (Sanz de Sautuola, 1980) destacan las conchas de algunos moluscos, especialmente del género Patella. Estudios recientes sobre los materiales procedentes de las excavaciones antiguas de Altamira indican la presencia en esas conchas de pintura roja consistente en hematites blanca, en cuya composición interviene arcilla micácea y cuarzo, posiblemente ambas más como colorante que como aglutinante (Cabrera Garrido, 1978). En el caso de Tito Bustillo, yacimiento al que volveremos más adelante, el análisis de pigmentos en alguna Patella indica la presencia de hematites micácea.

Finalmente, y siempre sobre la base de materiales no perecederos, las áreas de asentamiento proporcionan una ingente masa de industria de piedra tallada, parte de la cual se supone que 

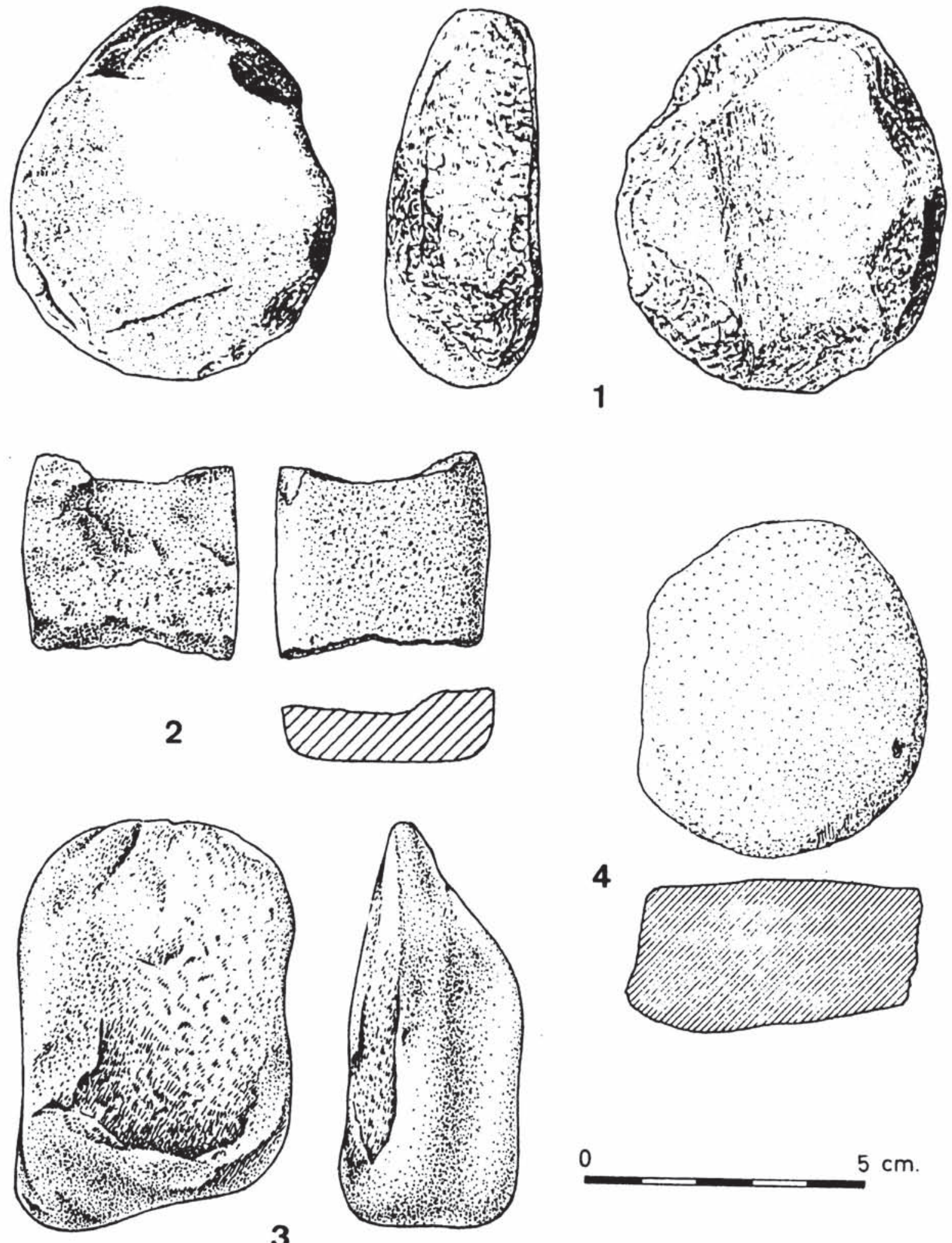

4

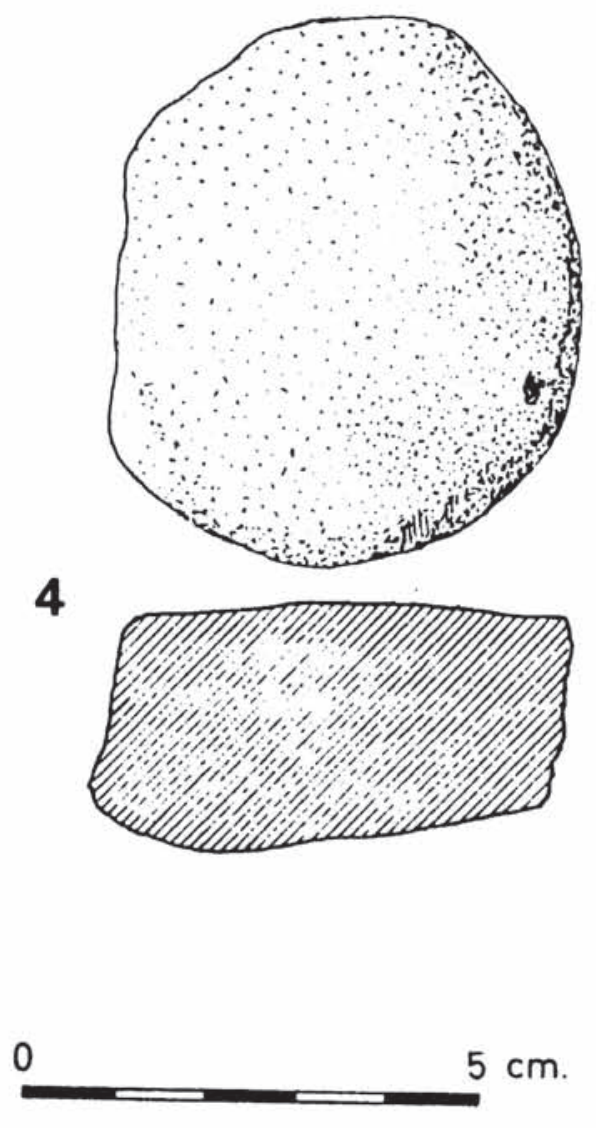

3

FIG. 2.- Area de estancia de la cueva de Tito Bustillo. Números 1 y 4, machacadores de ocre. Números 2 y 3, cantos de cuarcita, posiblemente empleados como lámparas. 
eventualmente ha podido ser utilizada para el grabado, ya sea sobre objetos mobiliares o sobrc paredes de la cueva. La ausencia de procesos de talla en las proximidades de los paneles decorados, parece indicar que esta manipulación se efectuaba en otros sectores de la cueva, o en talleres ajenos a ésta. Tampoco es sencillo establecer una relación funcional entre determinadas categorías de útiles y la decoración de las paredes. Tradicionalmente el grabado parietal se relaciona con los buriles, pero las experiencias de Lascaux parecen indicar que esto no siempre tenía que ser necesariamente así (Allain, 1979: 117-119), mientras que en Tito Bustillo, como describiremos más adelante, se detectan procesos de reavivado (golpes de buril) con huellas de haber sido empleados sobre superficies pintadas. En todo caso, el estudio funcional de material lítico de un yacimiento presenta de por sí las suficientes dificultades como para poder reconocer una utilización relacionada con el arte parietal. Estas eventuales relaciones resultarían aún más difíciles de estimar en el caso de una coincidencia topográfica entre el área de ocupación y el área de decoración, como sucede en los llamados "santuarios exteriores".

Este acercamiento a las actividades realizadas en áreas de asentamiento, debe lógicamente terminar reconociendo la imposibilidad de delimitar exactamente la mayor parte y de acercarse, siquiera remotamente, a otras muchas. En primer lugar, existen numerosos ejemplos de estructuras artificiales, no sólo de hogar, sino también de habitación (cabañas, muretes, cerramientos) o de función desconocida. Entre estas últimas cabría introducir las consideradas como "rituales" como puede ser el caso de las recientemente descubiertas en la cueva de El Juyo (Cantabria) (Freeman y González Echegary, 1981), Erralla (País Vasco) (Altuna, Baldeón y Mariezkurrena, 1984) o la fosa con una escultura femenina de Tito Bustillo (Moure Romanillo, 1982 b: 5-7 y 1984). A todo ello habría que añadir un larga lista de actividades o construcciones en materiales perecederos, que pueden detectarse de forma latente o, simplemente, pasar desapercibidas.

\subsection{Los espacios $\mathbf{y}$ áreas de tránsito}

Como su propio nombre indica, los espacios de tránsito se caracterizan por su carácter intermedio, de circulación ocasional por el interior de las cuevas. En el esquema más frecuente de una cueva decorada representa el espacio a recorrer entre el área de asentamiento (normalmente en la entrada, en zonas de luz exterior o de penumbra) y las zonas de arte parietal, que salvo en el caso de los llamados "santuarios exteriores" (abrigos y zonas de entrada a las cuevas, como La Haza y Pasiega B) o de penumbra, como Altamira, se encuentran en zonas de absoluta oscuridad. Los vestigios de actividad humana más frecuentes pueden agruparse en cuatro grandes apartados que integran las trazas físicas de desplazamientos, las indicaciones o referencias de itinerario, los hallazgos aislados - casuales o intencionales- y los testimonios de detención o aprovisionamiento.

El desplazamiento por las áreas de tránsito se testimonia a través de huellas o improntas humanas, pero también de los restos de iluminación y de eventuales roturas intencionadas de formaciones naturales para permitir el paso. Las huellas se presentan bajo la forma de improntas de pies, manos o de resbalones y deslizamientos. Hay ejemplos muy conocidos en numerosas cuevas decoradas o no, Tuc d'Audoubert, Montespan, L'Aldène, Fontanet, Niaux (Rèseau Clastres) y Pech Merle, en Francia, o Cueva Palomera, del complejo de Ojo Guareña (Burgos, España); ésta última en el contexto de unos restos de posibles antorchas datados por C-14 de los que se hablará más adelante. Recientemente ha sido localizado otro grupo de improntas de pies y manos en una cueva sin yacimiento arqueológico de la provincia de Palencia (España), y cuya localización exacta no ha sido dada a conocer por ahora, para evitar un posible riesgo de deterioro (Lám. I, 1) (Ortega Mateos, 1983). Salvo en un caso de Fontanet, siempre se trata de pies desnudos. Por lo que puede suponer en relación con el significado del arte parietal, conviene señalar la presencia de huellas infantiles, lo que parece excluir la reserva de estas zonas para individuos de alguna manera iniciados. 
Los vestigios relacionados, directa o indirectamente, con la iluminación de las áreas de tránsito son tan escasos como variados: restos de antorchas o de "tizonazos", diferentes tipos de lámparas, hogares de iluminación, etc. Como sistema más simple, el empleo de antorchas es también el más probable. No obstante, el carácter perecedero del material utilizable hace que la información sea escasa. Los testimonios indirectos más antiguos, fechados en el Paleolítico Medio, proceden de la cueva italiana de Toirano, y se encuentran en relación con una serie de improntas de pies atribuidas a la misma época. En la práctica totalidad de los casos los vestigios se reducen a "tizonazos" o manchas en suelos y paredes cuya relación con antorchas no siempre es evidente. En la cueva de Aldène algunos fragmentos de madera quemada han sido identificados como pertenecientes a enebro (Juniperus comunis), al que los estudios experimentales atribuyen una mayor eficacia como fuente de iluminación (Perles, 1977: 66-67). En España, la madera quemada procedente de antorchas y descubierta en la "galería de las huellas" de Cueva Palomera, antes citada, proporcionó una datación absoluta de 15.600 BP (Almagro Gorbea, 1974: 281; Bernaldo de Quirós y Moure Romanillo, 1978: 22-23).

Menos problemática parece la cuestión de las «lámparas" paleolíticas, aunque la variedad y subjetividad de los criterios de clasificación, basados en la presencia de una concavidad y/o restos de combustión implica que exista un buen porcentaje de atribuciones más que discutibles. Los ejemplos de su presencia son relativamente puntuales, y un elevado número de ejemplares, seguros o dudosos, tiende a concentrarse en yacimientos como Lascaux o La Gerenne de Saint Marcel (Allain, 1965; B. y G. Delluc, 1979). Una amplia documentación crítica sobre el tema puede encontrarse, además de en las obras citadas, en los trabajos de A. Roussot y S. de Beaume (1982-1984) y en especial en la tesis doctoral de esta última (Beaume, 1987). Intentando simplificar al máximo el problema, puede admitirse la posibilidad de lámparas fijas o estables en el caso de ejemplares de gran tamaño, como los de Saint Germain la Rivierè, Flageolet II, La Ferrassie, Lascaux, etc. (Beaume-Romera y Roussot, 1983), aunque en la práctica totalidad de los casos se trata de objetos móviles. A su vez, estos materiales portátiles pueden clasificarse en dos grandes grupos según se trate de ejemplares trabajados o esculpidos hasta obtener una especie más o menos cóncava, o de objetos naturales, que por lo general consisten en plaquetas de piedra, geodas, o cantos con alguna depresión.

Los estudios cromatográficos y espectrográficos realizados por A. Bourgeois en el marco del trabajo de S. Beaume-Romera indican la presencia de vestigios de carbón de madera, preferentemente resinosa, así como de grasa animal y de líquenes de musgo, utilizados verosímilmente estos últimos como mecha (Beaume-Romera 1984). El análisis de un ejemplar de Les Fees señala la presencia de restos carbonosos identificables como grasa de suido o similar (Roussot y BeaumeRomera, 1982: 377). Resulta especialmente relevante la procedencia o ubicación de estas piezas, que -como señala tambien S. de Beaume-Romera- en un setenta por ciento de los casos proceden de lugares al aire libre o de zonas poco profundas de las cuevas.

Un papel similar al de las lámparas fijas - aunque obviamente no el único- sería desempeñado por hogares destinados en exclusiva o parcialmente a la iluminación. Su importancia también ha sido discutida y en muchas ocasiones no resultan fáciles de discriminar de los hogares de combustión relacionados a otras actividades (cocina, fuente de calor, preparación de colorantes o tecnología de la piedra).

La funcionalidad y viabilidad de los hogares como elemento de iluminación parece fuera de duda incluso en los empleados también en otras actividades domésticas o tecnológicas. Aquellos que estaban exclusivamente destinados a proporcionar luz pueden ser identificados por su estructura (tamaño, ausencia de piedras, muretes u otros elementos que pudieran ocultar el fuego), por la falta de vestigios de otras actividades (huesos, ocre, sílex) o por su posición en zonas profundas previsiblemente no habitadas.

En el interior de Le Portel y Marsoulas hay numerosos hogares dispersos que tal vez hayan sido utilizados como fuente de luz y/o para urepostar» las lámparas o las antorchas (Beaume, 1987: 52). De manera más esporádica aparecen en otras cuevas pirenáicas, como Labastide, Mas d'Azil, 
Montespan y Tuc d'Audoubert. Algunos de ellos conservan restos de cocina, testimonio sin duda de un ocasional consumo "in situ", y a veces han sido localizados en las proximidades de zonas decoradas de las que se hablará más adelante.

A todos estos vestigios de desplazamiento habría que añadir la rotura de formaciones naturales (estalactitas, estalagmitas, suelos, etc.) con el fin de facilitar el paso a lo largo de la cavidad. Hay además un buen número de señales de itinerario que pudieron actuar como indicaciones. Podrían definirse como un conjunto de modificaciones de origen humano destinadas a establecer referencias de orientación y/o circulación, barreras artificiales, o medios para superar accidentes naturales. Sin duda los más espectaculares son los balizamientos, de los que se han conservado escasos ejemplares, pero que muy probablemente se verian aumentados por un número considerablemente mayor en materiales perecederos. Destacan los de la sala de los macarroni de Tuc d'Audoubert y otros diez ejemplos claros referenciados por Clottes y Bégouen (1981: 175).

Algunas figuras tradicionales interpretadas como signos podrian también serlo como referencias topográficas. En varios lugares del sector oriental de la cueva de Tito Bustillo (Asturias) aparecen trazos pareados o puntuaciones en el arranque de pequeñas galerías decoradas. Trazos y signos más complicados, siempre en color rojo, indican por ambos lados el acceso al "camarín de las vulvas" (Balbín y Moure, 1981: 32). Tal vez tengan un significado semejante un grupo de puntuaciones, trazos pareados y digitaciones de la cueva de La Cullalvera (Cantabria) que contiene figuraciones situadas a más de 1.200 metros de la entrada. Un papel similar pueden jugar algunas roturas no fortuitas y no relacionadas con el acceso, de estalactitas, que eventualmente llevan trazos o restos de pinturas, como en el caso de La Lloseta y de la ya mencionada cueva de Tito Bustillo (Balbín y Moure, 1981: lám. VI), o las roturas intencionales señaladas por Camps (1972: 145). En ocasiones los fragmentos pueden aparecer formando pequeñas acumulaciones o incluso columnitas, como en el Salle Nuptialle de Tuc d'Audoubert.

También pueden considerarse como una parte del itinerario las barreras artificiales que aíslan determinados sectores de una cueva. Puede ser el caso del murete que separa Trois-Frères y Aven (Clottes y Bégouen, 1981: 160), o quizá el cierre de una de las galerías de la cueva de La Pasiega (Galería C) (Breuil, Obermaier y Alcalde del Río, 1913; González Morales y Moure Romanillo, 1984: 35). Aunque en este caso no pueda afirmarse su cronología paleolítica, existe una barrera, al parecer artificial, entre Kaite I y Kaite II, del complejo de Ojo Guareña (Uribarri y Liz, 1973: 175-184).

A lo largo de las áreas de tránsito no son infrecuentes los hallazgos de fósiles físicos o culturales, cuya presencia resulta imposible de explicar por causas naturales. Aunque es dificil establecer barreras dentro de estructuras naturales como las cuevas, cuya utilización ha estado bastante diversificada, se entiende que en este caso se hace referencia a los descubrimientos ubicados en áreas de itinerario (progresión, detención), y no en lugares de aprovisionamiento o de ejecución de obras de arte parietal. Cuando se trata de material arqueológico, suelen ser clasificados como ocultaciones o "escondrijos" pero tampoco es sencillo diferenciar esos "atesoramientos" de las pérdidas accidentales. El criterio tradicional de incluir entre los primeros los objetos menos comunes o de mayor valor artístico es excesivamente simplista, y aunque esa pueda ser una de las explicaciones, no hay que dejar de lado el carácter casual de muchas situaciones, o la posibilidad de que fuesen - simplemente- depositados en un lugar determinado con intención de una posterior recogida y reutilización, sin que esa, por cualquier motivo, fuese posible (Clottes y Bégouen, 1981: 181-182). Por otro lado, ninguna de las posibles posibilidades contempladas: ocultamientos o escondrijos, pérdidas y restos paleontológicos sin explicación natural, puede ser excluida en áreas de estancia, o en las propias zonas decoradas.

Por desgracia, la mayor parte de las cuevas con arte rupestre no han sido objeto de una detenida prospección que, eventualmente pudiera indicar la presencia de vestigios de este tipo. En unos casos ello puede atribuirse a la antigüedad de los descubrimientos, en épocas en que la documentación del arte parietal estaba comenzando y en las que, obviamente, existía otro tipo de prioridades en la investigación. En descubrimientos más recientes hay sin duda que achacarlo a una 
ausencia de planificación científica, a un trasiego excesivo y no dirigido de exploradores, o a la excesiva precipitación por facilitar el acceso masivo a las cavidades subterráneas.

No obstante, hay ejemplos en yacimientos franceses y españoles que presentan asociaciones más o menos cerradas de material arqueológico, paleontológico e incluso paleoantropológico, que pueden considerarse como ocultaciones o escondrijos. En el primer grupo destacan los depósitos de Labastide, con cinco hojas de sílex (Glory y Simonnet, 1947); Bébeilhac, tres hojas y dos azagayas de asta (Martel, 1955); Mas d'Azil, cuatro hojas y un arpón magdaleniense (Meroc, 1949); Trois-Frères, tres hojas (Bègouen, 1933); Montespan, una decena de piezas líticas y una punta ósea (Trombe y Dubuc, 1947), una plaqueta decorada de Trois Frères, azagaya, hojas y hojitas de Enlène (Clottes y Bégouen, 1981: 156), una azagaya sobre una cornisa o grieta, aún inédita, de la cueva cantábrica de La Clotilde y toda una serie de situaciones difícil de separar de las pérdidas puramente accidentales. La mayor dificultad reside en su datación excepto en casos como Mas d'Azil en que se cuenta con un fósil característico del Magdaleniense.

Entre los escondrijos formados por material paleontológico habria que incluir aquellos que -además de no poder explicarse sin la intervención humana- se ubiquen en una posición o contexto que haga suponer una respuesta intencional a un esquema determinado. En este grupo destaca el esqueleto de un salmón situado sobre una cornisa natural de la cueva de Fontanet, los restos de diversas especies en Enlène y el cráneo de zorro de Trois-Frères (Clottes y Bégouen, 1981: 185). En la cueva del Salitre (Cantabria) y en una pequeña grieta, fue descubierta una calota infantil perteneciente a un individuo de unos seis años, asociada a varias mandíbulas y restos animales, concretamente de un suido y varios cápridos, y a algunos fragmentos de ocre. Aunque su cronología resulta por ahora difícil de explicar, sus descubridores señalan que pueden pertenecer al Paleolítico Superior (Cabrera Valdés y Bernaldo de Quirós, 1981: 141-148), y, en todo caso, no parecen dejar mucho lugar a dudas respecto a su carácter intencional.

En el apartado de pérdidas habría que incluir cualquier tipo de hallazgo mobiliar cuya posición en un determinado sector o punto de la cueva sólo puede entenderse como accidental. Desde luego, no hay ningún motivo lógico que impida que un objeto paleolítico pueda extraviarse, tanto en áreas de estancia o de decoración como, lo que parece más probable, en los lugares de progresión, detención o aprovisionamiento entre ambas. En todo caso, es claro que su separación de los escondrijos intencionales resulta sumamente difícil, y tal vez el criterio, resida en el carácter de objeto aislado o, como apunta Rouzaud (1983: 132), en la posición de tránsito. Puede ser el caso de varios dientes de Tuc d'Audoubert (Bégouen y Breuil, 1958) o de numerosos hallazgos líticos u óseos descubiertos fuera de contexto en cuevas francesas o españolas.

Este comentario acerca de los espacios de tránsito puede terminar como una referencia a los testimonios o trazas de detención y aprovisionamiento. Se entienden como una parada ocasional no relacionada con la estancia prolongada ni con la decoración. A veces comporta alteraciones en el terreno con la construcción de estructuras, como hogares - a veces asociados a restos de cocinao la excavación de refugios y cubetas. La detención a veces tan sólo se refleja en huellas (huellas de pies o manos, de resbalones o de caídas) o auténticas improntas corporales, los hogares en zonas de oscuridad son especialmente frecuentes en contextos del Magdaleniense IV, como en Labastide, Montespán, Mas d'Azil, Le Portel, Tuc d'Audoubert, Enlène, Labouiche, etc. (Rouzaud, 1983: 131132). Las cubetas o refugios en arcilla no siempre son fáciles de diferenciar de las excavadas por los osos. Además de las de Fontanet y Labastide (Rouzaud, 1983: 129) puede citarse el ejemplo español de la cueva de La Griega (Segovia), aunque en este caso aparezca en un yacimiento con arte parietal paleolítico y postpaleolítico.

Tal vez sea posible introducir una última categoría de urestos paleontológicos sin explicación naturaly diferente a la comentada al hablar de los escondrijos, para los hallazgos que estarian diferenciados de aquellos por su localización en lugares de tránsito y su relación con un consumo o utilización inmediata, como puede ser, respectivamente, la explicación de los restos de reno y bisonte, o los cráneos de oso para extracción de colmillos de Tuc d'Audoubert. 


\subsection{Las áreas de decoración}

De un modo genérico, se pueden entender como tales los paneles o conjuntos de paneles decorados con pintura, escultura o grabado. En su distribución topográfica pueden coincidir con áreas de asentamiento, pero una buena parte de esos conjuntos - al menos de los conservadostiende a situarse en zonas oscuras, no habitadas regularmente. Esto es válido sobre todo para algunas fases concretas del Paleolítico Superior, donde parece evidente la intención de ocultar los santuarios, marcando su separación de las áreas de asentamiento habitual: este tema ha sido tratado de modo específico por A. Laming-Emperaire (1962) y A. Leroi-Gourhan (1971) siendo uno de los argumentos de cronología e interpretación empleados por este último autor.

Por todo ello, la presencia de ajuares mobiliares o de estructuras artificiales que se asocian a los paneles decorados se debe, en la mayoria de los casos, bien a actividades relacionadas con la ejecución de las representaciones artísticas, con su kuso» - sea éste el que fuera- o bien a ocultaciones o pérdidas, como los ejemplos descritos al hablar de las áreas de paso.

El acceso a los paneles para su preparación o para la ejecución de las tareas de grabado y pintura suele ser directo, desde el suelo contemporáneo a las representaciones. En este sentido, es preciso tener en cuenta cómo a veces la limitación del espacio utilizable puede tener efecto sobre el campo manual correspondiente, reduciendo proporcionalmente su radio. Es necesario destacar también el hecho de que, en ocasiones, la irregularidad de la superficie de las paredes o techos exige un punto de obervación preciso para ver las figuras en sus correctas proporciones, y no deformadas. Este punto, en buena lógica, coincide con el adoptado por el artista durante la realización de su obra. Un buen ejemplo de esta clase de anamorfismo aparece en una gran figura de caballo situada junto al gran panel de la cueva de Tito Bustillo (n. ${ }^{2} 63$, según la catalogación de Balbín y Moure, 1982: 72-73), que requiere estar tumbado de espaldas en el suelo actual y frente a la pared para restituir las proporciones adecuadas de la figura, fuertemente deformada cuando se observa desde un ángulo diferente.

En otras ocasiones, las zonas pintadas quedaban fuera del alcance directo de los artistas, por lo que se hacía necesario el uso de elementos artificiales de aproximación a aquellas. En los casos en que las características de las galerías lo permitían, el uso de andamios situados entre las paredes y apoyados en las mismas pudo ser común, y de hecho parece atestiguado en Lascaux (B. y G. Delluc, 1979). En cambio, hay casos en que las zonas decoradas requirieron estructuras exentas -posiblemente de grandes dimensiones- para acceder a ellas. Un buen ejemplo lo ofrece nuevamente la cueva de Tito Bustillo, donde toda la zona superior del gran panel se desarrolla a algo más de tres metros sobre el suelo arqueológico presuntamente contemporáneo de las pinturas. A esto hay que añadir que esa parte superior incluye dos figuras asociadas de caballos (n. 56 y 58 del catálogo de Balbin y Moure, 1982), de más de dos metros de largo cada una, que por su tratamiento hacen suponer que fueron pintadas desde algún soporte de dimensiones suficientes como para permitir al artista moverse y abarcar la totalidad de las mismas. El ejemplo nos señala la relación existente entre el tamaño de las figuras o composiciones y las dimensiones del soporte, en función de las. limitaciones del campo manual.

Por lo que se refiere a la iluminación artificial, ésta hubo de ser estrictamente necesaria en las áreas decoradas situadas fuera de las bocas de cuevas o zonas iniciales de penumbra de las mismas. Existen algunos restos de madera quemada en galería con decoración parietal que pueden interpretarse como testimonio de iluminación mediante antorchas para pintar o grabar (B. y G. Delluc, 1979: 121).

Las lámparas, como instrumento destinado expresamente a la iluminación, ya han sido tratadas en el apartado correspondiente a las áreas de tránsito. Solamente cabría añadir que, a pesar de todo, no son precisamente frecuentes los hallazgos de este tipo de objetos en las áreas de decoración. En algunas ocasiones se han citado «lámparas» fijas, realizadas aprovechando oquedades naturales de las rocas o coladas estalagmíticas, si bien sobre algunas de ellas pueden caber dudas razonables.

Un último elemento de iluminación a tener en cuenta son nuevamente los hogares, presentes en 
algunas zonas de decoración y que debieron contribuir a dar una iluminación ambiental que sería reforzada puntualmente mediante lámparas móviles. En su día fueron localizados hogares, por desgracia hoy desaparecidos, en el "Salon Noir" de la cueva de Niaux y en el suelo de Lascaux. En Fontanet, otros hogares de grandes dimensiones se extienden entre el panel de los signos y el bisonte policromo. También el nivel arqueológico situado bajo el panel principal (conjunto $\mathrm{X}$ ) de la cueva de Tito Bustillo incluye un hogar de dimensiones mucho más reducidas que se ubica en la periferia de la ocupación, en una posición privilegiada frente a la zona decorada, y que sugiere un uso como el descrito.

Dentro del análisis arqueológico de los vestigios presentes a áreas de decoración uno de los elementos fundamentales son los testimonios de las tareas de preparación de materiales necesarios para ejecutar las representaciones pintadas, grabadas o esculpidas. Al menos una parte importante de este trabajo se puede considerar complementario o continuación del realizado con la misma finalidad en las zonas de asentamiento.

En este sentido, un capítulo importante lo constituyen la preparación y/o utilización de los colorantes: los testimonios más directos están representados por fragmentos de colorante hallados al pie de los paneles o en relación con los mismos, como sucede en las cuevas de Tito Bustillo, Altamira, y Lascaux (Couraud y Laming-Emperaire, 1979) entre otras. En ocasiones se han encontrado instrumentos posiblemente utilizados en el proceso de preparación in situ (machacadores de ocre, restos diversos coń trazas de colorante, etc). Algunos de estos hallazgos han permitido definir con relativo detalle la composición de colorantes o su procedencia, como en los casos de Lascaux (Ballet et al., 1979), Altamira (Marti, 1977; Cabrera Garrido, 1978), o de otros yacimientos cantábricos (San Juan, 1985). En el caso de Altamira los análisis por difracción de Rayos $\mathrm{X}$ de muestras de colorante rojo permitieron identificarlo como limonita con algo de goethita, en tanto que la pintura negra de la misma cueva se obtenía a partir de óxidos de manganeso $\left(\mathrm{Mn}_{2} \mathrm{O}_{3}\right.$ o $\left.\mathrm{MnO}\right)$ o de carbón vegetal.

Otro ejemplo particularmente interesante de área de decoración es el de la Grotte de la Tête-duLion (L'Ardèche). Al parecer la cavidad fue utilizada en una sola ocasión o en un espacio de tiempo muy corto a partir de una antigua entrada hoy desconocida. Identificado el suelo desde el que se realizaron las pinturas (un bóvido, dos cabezas de cabra, un ciervo y grupos de puntuaciones) se han localizado sobre el mismo restos de carbón de madera (Pynus sylvestris) proveniente de un hogar de iluminación, y colorante. Huellas de ocre aparecen formando manchas de goteo de 2-3 $\mathrm{cm}$. de diámetro sobre el suelo arenoso, y su distancia del panel decorado indica que su origen está en la preparación o mezcla de color y no en la propia aplicación sobre la pared (Combier, 1984: 83).

Los colorantes minerales utilizados se presentan a veces bajo la forma de lo que han sido llamados «lápices», con un patrón característico que presenta una o varias facetas de huellas de abrasión (Lám. II, 2). En el caso del ocre no son el resultado de aplicar directamente el material sobre la pared a decorar, sino del proceso de reducción a polvo, que luego sería mezclado con un aglutinante, en la mayor parte de los casos agua, aunque también se ha detectado la presencia de otros elementos.

En ese estado semifluido la pintura resultante requiere de algún tipo de elemento contenedor para poder ser transportada y utilizada. Entre otros han sido mencionadas placas de piedra como "paletas" para colorante, recipientes naturales (por lo general conchas de moluscos) o facetados (los llamados morteros), bloques que hoy conservan alguna de sus caras cubiertas de pintura, o incluso accidentes naturales en los que ésta fue depositada. Entre los bloques conviene mencionar el que aún puede verse en el pasillo o galería "A* de la cueva de La Pasiega (Breuil y Obermaier, 1913) y entre los accidentes naturales una concavidad llena de pintura negra de la pared próxima al «santuario de los triángulos» de Cueva Palomera, del complejo de Ojo Guareña (Moure Romanillo, 1985: 102-105).

Por su parte, E. Pietsch, a partir de datos experimentales de K. Herberts, sugiere la aplicación del colorante en polvo seco o húmedo, directamente sobre la roca. A partir de la humedad propia de las paredes o techos de las cuevas se incorporaría directamente a la roca a tenor de un proceso químico que él llama «fresco naturab» (Pietsch, 1964: 73). 
Los restos óseos descubiertos al pie de algunos paneles decorados pueden tal vez indicar otras prácticas no determinadas (ofrendas, elementos rituales), pero en la mayor parte de los casos se trata de restos de alimentación correspondientes al periodo de trabajo en el lugar, y puede resultar de gran interés establecer comparaciones entre los tipos de restos y las especies presentes en áreas de decoración y los encontrados en las zonas de habitat de la misma caverna. En el caso de Tito Bustillo, del que hablaremos más adelante, los restos paleontológicos indican unas pautas de selección y de uso diferentes a las detectadas en el área de asentamiento.

\section{EL CONTEXTO DE ARTE RUPESTRE EN LA CUEVA DE TITO BUSTILLO (ASTURIAS, ESPAÑA)}

La cueva de Tito Bustillo forma parte de un importante conjunto cárstico situado en el concejo de Ribadesella, sector oriental de Asturias. En sus proximidades existen numerosos yacimientos del Paleolítico Superior, algunos de ellos con arte parietal. Se trata de un descubrimiento relativamente reciente (1968) en el que se han realizado excavaciones sistemáticas a partir de 1970 (Moure Romanillo, 1974, 1975 y 1979; Moure Romanillo y Cano Herrera, 1976, 1978 y 1979; García Guinea, 1975). Los estudios de arte rupestre se han efectuado en el marco de un proyecto global que comprende también el de los propios depósitos arqueológicos. Las pinturas y grabados han sido publicados por sectores hasta la redacción de una monografía de conjunto (Balbín Behrmann y Moure Romanillo, $1980 a$ y $b, 1981$ y $1982 a$ y $b$ ).

La estructura subterránea accesible hoy en día se corresponde realmente con dos bocas con yacimientos arqueológicos: La Cuevona y una entrada hundida en que se realizaban las actuales excavaciones. A ambos lados de una barrera natural, actualmente superada por las obras de acondicionamiento a las visitas turísticas, existen considerables diferencias en técnicas, estilos y motivos en las obras de arte parietal, lo que permite diferenciar dentro del actual trazado de la cueva dos sectores - oriental y occidental- correspondientes respectivamente a las áreas de asentamiento de la Cuevona y Tito Bustillo (Fig. 1).

Han sido aislados once conjuntos decorados, algunos de ellos con varios paneles, siete en el sector oriental y cuatro en el occidental. En el primero conviene destacar la desigual distribución de temas en las dos paredes de la galería principal: mientras que en una se alinean los signos pintados en rojo, en la otra aparecen exclusivamente grabados animales con ciertos sistemas de modelado o sombreado interior. Por el contrario, en el sector occidental, y con acceso a través de la antigua entrada y el área de asentamiento en que se han realizado las excavaciones, encontramos las pinturas policromas y los grabados ejecutados con técnicas más pormenorizadas.

Centrándose exclusivamente en el sector occidental, y en el tipo de problemas objeto de esta comunicación, conviene señalar la existencia de la ya mencionada área de asentamiento en una zona de luz de día - hoy sepultada por el derrumbe- y en un tramo de penumbra, así como de varias áreas de decoración coincidentes con los conjuntos VIII (Galería de los Caballos) y X (panel principal). En este último se conservan materiales y estructuras que son el objetivo principal de esta parte del trabajo. A lo largo de las galerías de la cueva no se han observado restos o vestigios de desplazamiento o detención, a no ser algunos signos y puntuaciones rojas que pueden ser interpretadas como indicaciones o referencias topográficas.

\subsection{Area de estancia}

La superficie excavada corresponde a una zona de penumbra de la primitiva entrada de la 
cueva, una boca de más de $15 \mathrm{~m}$. de luz cegada por un derrumbre producido inmediatamente después de su última ocupación magdaleniense, o incluso durante la misma. Los trabajos se han centrado en un tramo situado tras un ángulo de la pared ubicado en torno a unos $20 \mathrm{~m}$. de la vertical de la boca. Junto a la zona excavada encontramos la primera de las pinturas rojas del conjunto XI, que se consideran técnicamente similares a las de las primeras fases del panel principal.

La excavación ha seguido una orientación fundamentalmente extensiva, y por ello no se ha intentado profundizar hasta la base de la estratigrafía arqueológica. Hasta el momento se han localizado dos niveles, el más reciente de los cuales incluye al menos un suelo de ocupación y puede ser subdividido en varias capas $(1 \mathrm{a}, 1 \mathrm{~b}, 1 \mathrm{bc}, 1 \mathrm{c} .1,1 \mathrm{c} .2,1 \mathrm{c} .3$ y $1 \mathrm{c} .4)$, todas ellas pertenecientes a un estadio inicial del Magdaleniense Superior con arpones de una fila de dientes.

Tanto los estudios faunísticos como los polínicos parecen indicar su utilización durante etapas de clima riguroso. Las dataciones de Carbono 14 han dado resultados no consecuentes con la ordenación estratigráfica a partir de muestras realizadas con diferentes tipos de material (carbón vegetal, conchas de moluscos y esquirlas óseas). Los resultados son los siguientes:

\begin{tabular}{cclll}
\hline Nivel & Capa & Ref. Laboratorio & Edad BP. & \multicolumn{1}{c}{ Material anallzado } \\
\hline 1 & a & CSIC 154 & $14.240 \pm 300$ & Carbón vegetal. \\
1 & a & CSIC 155A & $15.180 \pm 300$ & Conchas de molusco. \\
1 & a & CSIC 155B & $15.400 \pm 300$ & Conchas de molusco. \\
1 & a & CSIC 261 & $14.220 \pm 180$ & Carbón vegetal. \\
1 & b & GrN 12753 & $14.930 \pm 70$ & Carbón vegetal. \\
1 & c & I 8331 & $13.870 \pm 220$ & Fragmentos óseos. \\
1 & c & I 8332 & $13.520 \pm 220$ & Fragmentos óseos. \\
2 & - & Ly 4212 & $14.890 \pm 410$ & Fragmentos óseos. \\
\hline
\end{tabular}

Además de la no consecuencia de las fechas, el conjunto de las cronologías es anterior a la casi totalidad de las obtenidas en Magdaleniense con arpones, y por el contrario, bastante próximo al de otros niveles cantábricos clasificados como Magdaleniense Inferior o Medio (Rascaño, Altamira, El Juyo, Entrefoces, La Viña, Las Caldas). En el caso de que las fechas de Tito Bustillo o el intervalo que representan se consideren admisibles, tal vez la explicación haya que buscarla en cuestiones de variabilidad o en el carácter no lineal de este complejo magdaleniense. En todo caso, las soluciones pasan por contrastar los resultados arqueológicos con nuevas dataciones, estudios paleoecológicos y en especial con los análisis de sedimentos.

En la secuencia indicada pueden seguirse pequeñas diferencias en la composición global del utillaje que permiten diferenciar dentro del nivel 1 dos complejos, el superior, formado por las capas 1a a 1c.1, y el inferior, con las capas 1c.2, 1c.3, y 1c.4. Las diferencias tecnológicas entre ambos son ciertamente sutiles y se reflejan cuantitativamente en el material lítico. A lo largo de todo la serie se repiten constantes como el predominio de los buriles -especialmente de los diedros- sobre los raspadores, la presencia entre estos últimos de numerosos raspadores simples en extremo de hoja no retocada y el elevado porcentaje de hojitas. En el llamado complejo inferior el predominio de buriles sobre raspadores es más acentuado que en el superior, y dentro de él los tipos sobre truncatura tienden a cercarse a los diedros, al mismo tiempo que el indice microlaminar alcanza el 59,9\%. Faltan los elementos anunciadores del Aziliense (disquitos, raspadores unguiformes) y los geométricos (sólo un trapecio en el tramo antiguo). Algunos tipos considerados fósiles característicos, como el buril de pico de loro, aparece puntualmente en varias capas de ambos complejos: uno en 1a, dos en $1 b$ y dos en $1 c$. 
En industria ósea el recuento de cinco grupos de útiles «tipológicos» (azagayas, varillas semicilíndricas espátulas, agujas y arpones) que suman un total de 380 objetos, no muestra diferencias apreciables a lo largo de la secuencia, en que todos ellos -excepto los arpones- aparecen en proporciones casi idénticas. El único arpón del complejo inferior presenta dientes curvos poco marcados - aunque no puede considerarse un protoarpón- y un tipo de base o enmangue bastante atípico.

En lo que concierte a las azagayas, sobre un total de 214 piezas completas o fragmentadas, 78 conservan bases identificables (47 de complejo superior y 31 del inferior). En todos los casos predominan las bases biseladas y dentro de ellas los biseles simples, que no obstante descienden desde el $70 \%$ en el complejo inferior al 51 en el superior. Este retroceso viene compensado por el aumento de los tipos de doble bisel y de las apuntadas. Los tres únicos ejemplares típicos de azagayas de base ahorquillada pertenecen a las capas superiores. Tampoco las secciones ofrecen cambios apreciables, excepto el ligero aumento de circulares y la reducción de las triangulares.

Entre las actividades detectadas en relación con las respuestas tecnológicas conviene señalar la evidencia de algunos restos de extracción de varillas y agujas de asta en varias zonas de la capa $1 \mathrm{~b}$, en especial en cuadrículas próximas al afloramiento de uno de los bloques, que pudo favorecer un área de trabajo de este tipo. Entre estos vestigios de tecnología ósea, destaca una espátula con temas animales (dos caballos) en proceso de fabricación, cuyo estudio resulta especialmente ilustrativo para conocer los procesos de manufactura y decoración de este tipo (Moure Romanillo, $1982 a$ : 669-672).

Tito Bustillo ha proporcionado también una importante serie de piezas de arte mueble. Los objetos con motivos figurados se concentran en el complejo superior y en especial en la capa 1b, como consecuencia sobre todo de la concentración de plaquetas grabadas (Moure Romanillo, 1982 b), aunque que hay otras piezas espectaculares, como una escultura-colgante en bulto redondo que representa una cabeza de cabra y dos estilizaciones femeninas (Moure Romanillo, 1983 y 1984). Los motivos decorativos están presentes en toda la secuencia, y tan solo se señalan diferencias cuantitativas entre los colgantes. No obstante considerando la mayoría absoluta de soportes naturales (conchas, dientes) y el elevado número de piezas necesarias para construir un collar, un casquete o un brazalete, se entiende que esas diferencias son irrelevantes.

La actividad económica representada por los restos de vertebrados tampoco indica diferencias significativas dentro de la secuencia de capas del nivel 1. El ciervo fue, con diferencia, la especie más consumida en todos los momentos de esta parte de la ocupación. Se aprecia tan sólo un ligero descenso hacia las capas más recientes, que se compensa con un incremento también muy reducido, del gran bóvido, el caballo y sobre todo de la cabra (Altuna, 1976: 155).

El material arqueológico, tanto lítico como óseo, en especial determinados útiles tipológicos de asta (varillas semicilíndricas, azagayas ahorquilladas), los objetos de arte mueble y algunos temas decorativos sobre soportes diversos nos muestran un mundo bastante próximo al representado en algunos niveles clasificados en el Magdaleniense Inferior o Medio. La presencia de arpones sugirió desde un principio, y desde la perspectiva de un modelo clásico de periodización, su pertenencia al Magdaleniense Superior, aunque el resto del instrumental y las propias dataciones absolutas apuntan hacia un estadio arcaico o inicial de esa fase. Desde luego, desde un punto de vista menos unilineal, encaja perfectamente en un contexto cántabro-pirenaico caracterizado entre otras cosas por determinados elementos del arte mueble (contornos recotados, esculturas en bulto redondo, plaquetas decoradas, etc.), que puede relacionarse con el Magdaleniense Medio y Superior inicial de la secuencia clásica (Moure Romanillo, 1988).

Dentro de esta área de estancia existen varios elementos que pueden ser correlacionados con el arte parietal. Además de los objetos de arte mueble, susceptibles de comparación estilística, y de los datos paleoecológicos, que proporcionarían en todo caso una referencia circunstancial, indirecta e incompleta, hay algunos elementos relacionados con la preparación del colorante y con el acceso hasta las zonas decoradas. Los fragmentos de colorantes minerales aparecen tanto en estado bruto como con restos de abrasión o facetado, bajo la forma de lo que común e impropiamente se 
conocen como «lápices» (Lám. II, 2). El análisis de una serie de muestras procedentes de esta zona de excavación ha sido realizado por C. San Juan en el Departamento de Prehistoria de la Universidad de Cantabria y los resultados pueden resumirse de la siguiente forma:

\begin{tabular}{|c|c|c|c|c|}
\hline Muestras & Cuadro & Capa & Materlal(s) & Color (Cailleux) \\
\hline$a \cdot b$ & $\mathrm{XI}-\mathrm{B}$ & $1 b$ & Hematites & $\mathrm{R} 17 / \mathrm{S} 17$ \\
\hline c & XI-B & $1 \mathrm{~b}$ & Arcilla con óxidos de hierro & N39 \\
\hline d & $\mathrm{XI}-\mathrm{B}$ & $1 \mathrm{~b}$ & Hematites y arenisca (lápiz) & $\mathrm{R} 17 / \mathrm{S} 17$ \\
\hline e & $\mathrm{XI}-\mathrm{C}$ & 1c.2 & Hematites micáceo (lápiz) & $\mathrm{R} 15 / \mathrm{S} 19$ \\
\hline $\mathrm{f}$ & $\mathrm{XI}-\mathrm{C}$ & 1c.1 & Hematites micáceo (lápiz) & P13/P15 \\
\hline $\mathrm{g}$ & $\mathrm{XI}-\mathrm{C}$ & 1c.1 & Hematites y arenisca & $\mathrm{R} 17 / \mathrm{S} 17$ \\
\hline $\mathrm{h}$ & XII-C & $1 c .2$ & Arcilla blanca y manganeso & - \\
\hline $\mathrm{i}$ & $\mathrm{XI}-\mathrm{C}$ & $1 c .2$ & Hematites & P15/R15 \\
\hline $\mathrm{j}$ & XII-C & lbc & Restos de concha impregnada & P13/P15 \\
\hline k-1 & \multicolumn{3}{|c|}{ Utilización como colorante poco probable } & L77-M35 \\
\hline $\mathrm{m}$ & $\mathrm{X}-\mathrm{B}$ & 1a & Hematites & P15 \\
\hline$q$ & XIV-C & $1 c .1$ & Hematites y arcilla & N13 \\
\hline $\mathrm{r}$ & XII-C & $1 c .1$ & Conchas de Patella impregnadas & - \\
\hline $\mathbf{s}$ & XIV-C & 1c.2 & Hematites (klápiz*) & S15 \\
\hline $\mathrm{t}$ & $\mathbf{X}-\mathbf{B}$ & 1a & Hematites («lápiz») & $\mathrm{S} 13$ \\
\hline
\end{tabular}

Además de estos fragmentos de colorante y de numerosas manchas localizadas sobre diversos materiales y en diferentes puntos del área excavada pueden mencionarse otros elementos mobiliares relacionados con la pintura: yunques, machacadores y paletas. Entre los primeros destaca el ya mencionado bloque de la capa la que aparece totalmente cubierto de colorante rojo, y cuya morfología recuerda el también citado de la galería A de la Cueva de la Pasiega. Hemos interpretado como machacadores al menos dos cantos que presentan numerosas huellas de raspado y percusión e impregnaciones de colorante (Fig. 2, números 1 y 4). Otros cantos y fragmentos de piedra conservan manchas rojas o negras de procedencia intencional menos clara. Las llamadas "paletas" o recipientes para la pintura son en este caso siempre naturales, ya se trate de conchas de moluscos (en especial del género Patella) o de placas de pizarra o arenisca. Entre las segundas destaca una totalmente cubierta de colorante rojo tipo oligisto micáceo. Por supuesto, y con independencia a su empleo como colorante, la presencia de numerosos vestigios de ocre en un zona en que está documentada una intensa actividad en tecnología ósea puede también explicarse por su empleo como abrasivo en el trabajo del asta.

No han sido descubiertas lámparas facetadas, pero hay al menos tres objetos que pueden relacionarse funcionalmente con las mismas. El primero es una plaqueta con una cara ligeramente rebajada mediante piqueteado, y que conserva una intensa coloración negruzca. Las otras dos son cantos de cuarcita fracturados y con una depresión posiblemente natural, en la superficie de rotura (Fig. 2, números 2 y 3).

\subsection{Area de decoración de la cueva de Tito Bustillo}

Aunque faltan vestigios de tránsito o detención, la cueva de Tito Bustillo puede ejemplificar una de las pocas áreas de decoración descubierta y relativamente bien conservada en la costa cantábrica española. Como en otros casos, el hallazgo se produjo de una forma casual, siendo observada en corte la presencia de un pequeño nivel de color morado durante la limpieza de arenas en la llamada 
«sala de las pinturas». Este conjunto decorado se corresponde con el número $X$ de las publicaciones sobre arte parietal de Balbin Behrmann y Moure Romanillo (1982 a), y en él coinciden la casi totalidad de los polícromos de la cueva y la única serie reconstruida de superposiciones (Balbín y Moure, 1983) (Lám. I, 2).

El área fue excavada en 1970 por M. A. García Guinea, y los materiales dejados sobre el terreno hasta su recogida definitiva en octubre de 1984. Entre otras observaciones del primer excavador de la cueva destacan las de contemporaneidad con el panel decorado, la presencia de materiales colorantes y buriles relacionables con la ejecución de pinturas y grabados y el carácter parcial del depósito estudiado, tanto por el supuesto hundimiento de parte del suelo como por no haberse excavado la totalidad de la sala (García Guinea, 1975: 20-21; Almagro Basch, García Guinea y Berenguer, 1973). Durante los trabajos fue obtenida un datación absoluta con Carbono 14 (CSIC 80: $14350 \pm 300$ BP) (Almagro Basch, García Guinea y Berenguer Alonso, 1973: 471) y posteriormente otra de arqueomagnetismo cuyo resultado fue 14800 años BP (Kopper, 1973: 319; Bernaldo de Quirós y Moure Romanillo, 1978: 23-24). No obstante, en una publicación posterior en la revista "Science* se da la fecha 11.200 BP. como resultado, al parecer, de la misma datación paleomagnética (Kopper y Creer, 1974: 348-350).

Por diversas razones, los primeros sondeos estratigráficos y esta excavación en el área de pinturas de la cueva de Tito Bustillo, quedaron interrumpidos al poco tiempo. En lo concerniente al depósito situado debajo del panel principal no cabe duda de que, cuando menos, se desperdició una oportunidad sumamente infrecuente de realizar un estudio de material arqueológico, paleontológico y de estructura relacionado de manera directa con zonas decoradas.

El propósito del trabajo iniciado por nosotros en octubre de 1984, y del que ofrecemos un avance, consiste fundamentalmente en el estudio del área de decoración de la cueva de Tito Bustillo mediante el análisis pormenorizado de las actividades efectuadas en el mismo a través del estudio tipológico y funcional de la industria lítica, la clasificación de los restos faunísticos, la identificación de materiales colorantes y, en su caso, la interpretación de las estructuras. Al mismo tiempo, se intentó la obtención de una nueva fecha absoluta a partir de fragmentos óseos inidentificables.

Hasta el presente se ha defendido que esta zona de actividades especializadas es contemporánea del Magdaleniense Superior del área de asentamiento en proceso de excavación. Teniendo en cuenta el carácter arqueológicamente indeterminable del escaso material situado bajo el panel, esta correlación se apoyaría en la coincidencia de fechas absolutas y motivos decorativos en algunos objetos de arte mobiliar, y en la presencia de idénticos tipos de plaquetas grabadas. A su vez, el nivel 1 del yacimiento de habitat presenta ciertas relaciones indirectas con el panel decorado, como el clima riguroso al que corresponde, que puede ir muy bien con la presencia de reno en el gran panel (Moure Romanillo, 1980), y la coincidencia en técnica, estilos y convencionalismos entre objetos de arte mueble y grabados parietales (Balbin y Moure, 1982 a: 88-89).

En el suelo del área de decoración fueron localizados tres colgantes naturales consistentes en otras tantas conchas de Trivía europea con dos perforaciones. Estas cuentas son también las más frecuentes en el yacimiento de entrada, en que aparece en todas sus capas (Deibe Balbás, 1985: 204207) (Fig. 4, 8).

Como cuestión previa al trabajo y a la futura excavación del suelo intacto de la sala, se procedió a una planimetría detallada de la misma y a su subdivisión en áreas o cuadrículas de un metro cuadrado. Para evitar confusiones con la excavación en el área de asentamiento de la entrada, éstas han sido denominadas a partir del punto cero utilizando números arábigos y no romanos como en aquella (Fig. 1). Estas cuadrículas se superponen a las áreas diferenciadas, de manera al parecer arbitraria, en las primeras excavaciones.

\subsubsection{Area de hogar (Fig. 3)}

La única estructura interpretada hasta el momento es un hogar situado en las cuadrículas 9B, 10A y 10B de la actual subdivisión en áreas de la sala del panel, y que corresponde a su vez a la 


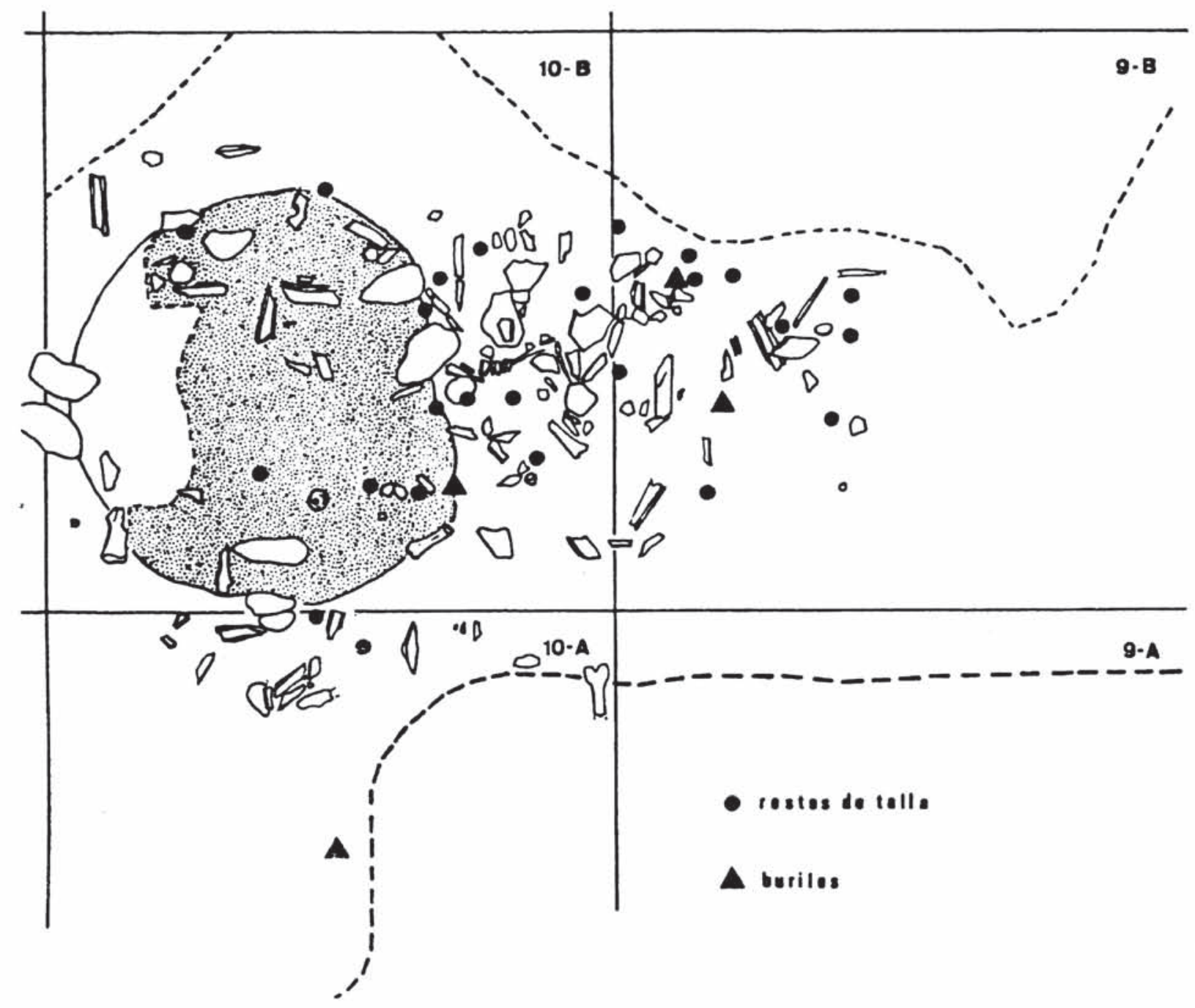

Fic. 3.- Planta de hogar de iluminación del área de decoración de la cueva de Tito Bustilla.

zona $A$ de las excavaciones de 1970. A partir de la limpieza efectuada en octubre de 1984, la identificación no parece dejar lugar a dudas: se trata de un hogar plano, de planta circular de 60/65 $\mathrm{cm}$. de diámetro, parcialmente destruido en su sector $\mathrm{NE}$, aunque perfectamente reconocible su forma circular. En su interior no se conservan bloques ni cantos y sólo se localizan cuatro pequeños fragmentos de caliza en dos grupos situados en la periferia. La mayor concentración de material arqueológico y paleontológico se encuentra en la parte SW del hogar, aunque dadas las condiciones de excavación no puede descartarse su prolongación por un zona desaparecida o incluso - aunque menos probable - por la zona intacta situada bajo el testigo desde el que actualmente se explica el panel a los visitantes.

El registro y recogida de materiales permitió ante todo una planimetría detallada del hogar y la clasificación de los mismos. El inventario de industria de piedra tallada presenta, sin embargo, ciertas diferencias con el publicado en la primera memoria (García Guinea, 1975), diferencias que implican especialmente a la clasificación de los útiles (el número real de verdaderos buriles es 
mucho menor) y la ausencia de algunos fragmentos de talla. Del total de piezas recuperadas en el área del hogar, doce son productos de talla -ocho lascas (cuatro de sílex y cuatro de cuarcita), dos hojas y dos hojitas- y seis útiles. De estos últimos, aunque el número absoluto es inferior al identificado por García Guinea (1975: 22-23) la mayor parte son buriles y todos ellos diedros: dos ladeados, uno múltiple y otro de ángulo sobre rotura, a los que hay que sumar un bec, un borde de núcleo y un golpe de buril. El estudio preliminar de huellas de uso indicó la presencia de microestrias en todos los ángulos del buril, y de vestigios de material colorante rojo en el bec, uno de los buriles diedro, el golpe de buril y el borde de núcleo (Láms. II, 1 y III), lo que parece indicar su empleo sobre la pared pintada y la existencia de un proceso de reavivado sobre el terreno.

Entre los objetos registrados en el plano de la campana de 1975 se indican varias plaquetas decoradas, una de las cuales (Fig. 4 n. ${ }^{2}$ 12), presenta además grabados semejantes a los descubiertos en el nivel $1 \mathrm{~b}$ (Magdaleniense Superior inicial) del área de asentamiento de la antigua entrada de la cueva (Moure Romanillo, 1982 b: Balbin Behrman y Moure Romanillo, 1982 a: 92, fig. 27, 4), lo que constituye un elemento más de la relación entre ambas zonas. La industria ósea de este sector se limita a un punzón.

En el contexto del hogar se conserva un único fragmento de material colorante, correspondiente al sector 2 de cuadro 10B. Se trata de una muestra de ocre sin huellas de uso formada por hematites asociado a arenisca de grano fino de buena capacidad de pigmentación y color-raya P15P17 de la tabla de Cailleux (San Juan, 1985).

La situación del hogar, que ocupa un posición central en la sala bajo la bóveda en que se concentran los policromos y la mayor densidad de grabados, y la ausencia en el mismo de bloques o estructuras que dificulten la difusión de la luz, demuestra su papel, cuando menos prioritario, como fuente de iluminación. Los escasos restos óseos descubiertos sobre el hogar sólo indican un empleo ocasional relacionado con la preparación de alimentos durante la utilización del área y, por tanto, de la ejecución del panel. Asimismo, la presencia de un fragmento de ocre y de numerosos vestigios de color, además de demostrar la elaboración de pintura sobre el terreno, puede apuntar el empleo del fuego para la preparación del material utilizado para las mismas (Perlés, 1977: 62). En todo caso, parece claro que la duración del hogar fue bastante breve, sin punto de comparación con las grandes estructuras de combustión del área de asentamiento.

\subsubsection{Resto de la sala}

El resto del área excavada está separado de la zona del hogar por una depresión producida por los primeros trabajos de excavación bajo las pinturas para rebajar el suelo, según se explicaba antes; de ahí que las zonas de concentración de material aparezcan en el plano como separadas por áreas vacías de contenido arqueológico. En todo caso la densidad de materiales parece ser muy variada, y dado que desconocemos con seguridad hasta qué punto lo conservado en superficie al inicio de la campaña de 1984 se corresponde con la distribución original, se debe tomar con cautela cualquier conclusión sobre las características de esa dispersión de materiales.

Por otra parte, también hemos podido verificar en esta zona que el recuento de los materiales recuperados durante la breve campaña de 1984 tampoco se corresponde directamente con los señalados por García Guinea en su publicación (García Guinea, 1975) que, según dicho autor, quedaron depositados in situ tras ser debidamente recogidos y dibujados. Dado que en los planos de la mencionada publicación no se señalaban coordenadas de ningún tipo, resultó difícil identificar con detalle las piezas indicadas en ellos con las presentes en el suelo del yacimiento. Si a ello se une el tiempo transcurrido entre ambas excavaciones y el deterioro sufrido por esa zona como resultado del paso de personas y la realización de algunas obras de acondicionamiento, resulta explicable un cierto grado de diferencia entre ambos recuentos.

Cuestión aparte es la de la clasificación del material. Si se comparan las listas de útiles líticos recogidos en 1984 y los ya publicados en 1975 se hacen evidentes algunas diferencias importantes: 

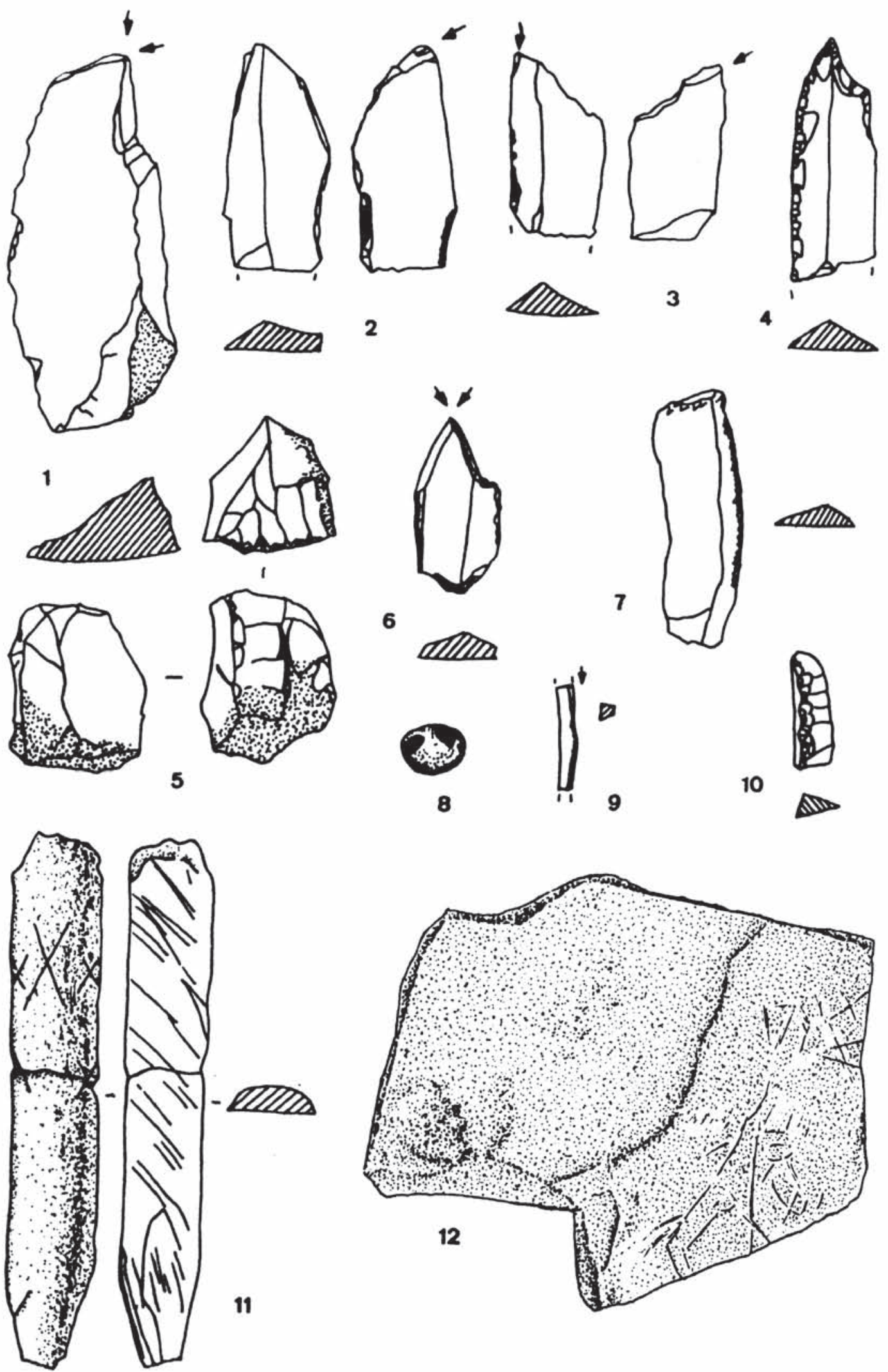

FIG. 4.- Industria y objetos de adorno y arte mueble del área de decoración de la cueva de Tito Bustilla. 
la más llamativa es, sin duda, la menor cantidad de útiles retocados en nuestra colección. Está claro que varias de las piezas clasificadas como buriles en 1975 eran en realidad restos de talla sin retocar, perfectamente identificables a través de las ilustraciones. Por otro lado, no ha sido posible localizar algunas de las piezas que aparecen en dichas ilustraciones o en los dibujos de los planos de la campaña de García Guinea (Fig. 4).

Dado lo reducido del recuento total de materiales líticos de la zona, es evidente que no se pueden generalizar las conclusiones derivadas de su análisis cuantitativo. Por contraste con el área de ocupación de la entrada, sin embargo, destacan algunos hechos. En primer lugar, hay un manifiesto predominio de sílex como materia prima (64 piezas de sílex frente a 9 de cuarcita), en tanto que los porcentajes de ambas materias, considerados en número de restos de talla, en los niveles del yacimiento de la entrada, tendian a estar casi equilibrados (Moure Romanillo, 1975: 2021; Moure Romanillo, 1976: 114).

Dá la impresión de que este fenómeno puede estar relacionado directamente con el hecho de que la totalidad del utillaje retocado presente en la zona del panel se realizó en sílex, recalcando el carácter de conjunto «cerrado" que se relaciona directamente con la gama concreta de actividades realizadas en esa zona. En ese mismo sentido, la relación entre restos de talla y útiles es netamente distinta entre el área de ocupación y la zona bajo las pinturas, siendo mucho mayor el porcentaje de útiles en esta última (entre 10.1:1 en la primera y 3.8:1 en la segunda).

La composición de los restos de talla también es, como cabía esperar, muy distinta de la registrada en el yacimiento de ocupación: por lo que respecta al material de sílex, hay una proporción relativamente elevada de hojas, hojitas y golpes de buril, que casi se equilibra con las lascas; en cuarcita, sin embargo, éstas representan la práctica totalidad del material.

Entre la industria ósea, el único útil tipológicamente definible es una varilla semicilíndrica con inicio de base redondeada y extremo apuntado, que encajaría en el tipo 26.1 de la clasificación de I. Barandiarán (1967: 307-308) (Fig. 4, 11). En la superficie convexa lleva varios motivos en aspa y la plana está cubierta de líneas oblicuas. El tema de las aspas aparece en diferentes episodios del Magdaleniense Cantábrico: sobre un objeto del Solutrense o Magdaleniense, cuatro del Magdaleniense III, tres del Magdaleniense IV, uno del Magdaleniense V y tres del Magdaleniense VI (Barandiarán Maestu, 1973: 287). A ellos se sumarian los descubiertos posteriormente en Tito Bustillo, en que el mismo motivo aparece en la cara dorsal de una varilla de la capa 1c.2, y sobre azagayas de la capa $1 \mathrm{~b}$ y del nivel 2. Los trazos oblicuos sobre la cara plana de otras varillas aparecen en las capas $1 \mathrm{~b}$, $1 c .2$ y 1 c.1 de Tito Bustillo, en esta última sobre dos ejemplares.

En cuanto a la dispersión horizontal de las piezas, parece evidente en un primera observación de las zonas de mayor concentración de material lítico no se corresponden exactamente con aquellas de mayor abundancia de restos óseos. También en la zona del hogar los restos de talla y los útiles se situaban preferentemente en la periferia del mismo, así como la mayor concentración de huesos.

En relación con las materias primas empleadas, y proporcionalmente al número de restos de talla existentes hay mayor presencia de restos de cuarcita en la zona del hogar (5 sobre un total de 16) que en la zona bajo las pinturas ( 3 sobre 52$)$.

La distribución de tipos de útiles no ofrece ninguna sorpresa: de aquellos que han sido recogidos con datos precisos de coordenadas bajo las pinturas, 9 son buriles, 2 son raspadores, y hay un dudoso perforador y una hoja de truncatura recta. A ellos habría que añadir una pieza de retoque continuo sobre dos bordes del cuadro 14D, sin más precisiones. Todos los útiles han sido realizados en silex, tal y como ya se ha señalado antes. Resulta interesante comprobar que, a diferencia de los restos de talla, los útiles tienden a coincidir en su dispersión con las zonas de mayor abundancia de huero.

El suelo de la zona, por otra parte, se hallaba impregnado de colorantes: en algunos puntos la arcilla presentaba un tono rojo intenso, o bien negro, superponiéndose en algunas ocasiones y sin que fuera posible delimitar con precisión la extensión de estas manchas, dado que la superficie estaba, como ya se ha dicho, bastante alterada. La muestra recogida en la cuadrícula $13 \mathrm{C} / 7$ corresponde a arcilla coloreada con óxidos de hierro, con poco poder de pigmentación. El color 
corresponde al M/45 de Cailleux. Este colorante pudiera ser un resto de tareas de preparación in situ, pero si se tiene en cuenta que parte de la zona que tratamos queda bajo las pinturas, parece más probable atribuir su presencia a la ejecución de las mismas. La fuerte impregnación del suelo supone que la pintura estaba en estado líquido, como puede corresponder al goteo directamente desde el techo o desde los recipientes manipulados sobre ese suelo.

Los restos de fauna existentes en toda la zona bajo las pinturas estaban extremadamente fragmentados, por lo cual buena parte de ellos resultaron de imposible determinación. Las piezas identificables sumaban un total de 90 , de las cuales más de la mitad correspondian al género Capra (50 restos) seguido en orden decreciente por el Cervus elaphus (15 fragmentos). Completan el recuento seis restos de Ursus, tres de bóvido y uno solo de lobo, liebre y ave sin identificar. Las determinaciones de la fauna, aún provisionales, han sido realizadas por el Dr. Morales Muñiz, del Departamento de Zoología de la Universidad Autónoma de Madrid.

Esta composición de fauna contrasta con la recogida en los niveles del área de ocupación. Significativamente hay más restos de cabra bajo el panel de las pinturas que en la totalidad de los recuentos publicados del área de ocupación (Altuna, 1975), correspondientes a las campañas de 1972-1975, en que predominan ampliamente los ciervos. El tipo de parte anatómica representado por los restos de cabra parece indicar que no se limitaban a transportar hacia el interior de la cueva has extremidades sino animales completos, de los que se conservan un cierto número de vértebras, dientes y un fragmento de mandíbula. Por el contrario, todas las determinaciones de caballo corresponden a extremidades y las de gran bóvido a un húmero y dos dientes, en tanto que las piezas de ciervo son algo más variadas. Entre los restos de este último hay mayoría de extremidades pero también varias vértebras y un fragmento de mandíbula (Fig. 5).

Salvando la fragmentación y el carácter limitado de la muestra, tal vez sea significativo el hecho de que los animales de mayor talla (caballo, gran bóvido) estén solo representados por restos de extremidades, los de talla mediana (ciervo) por algunas vértebras, y los de talla pequeña (concretamente las cabras) por todo tipo de restos (Figs. 6 y 7). Estas diferencias podrían estar en relación con las mayor dificultad de trasladar grandes masas de carne procedentes de piezas de mayor tamaño a lo largo de más de un centenar de metros por el interior de la cueva.

\subsubsection{Cronologia}

Ya sea a causa del carácter esporádico y especializado de la actividad llevada a cabo en el área, o por cuestión de conservación diferencial, los materiales disponibles no son lo suficientemente diagnósticos para su clasificación atendiendo a criterios arqueológicos.
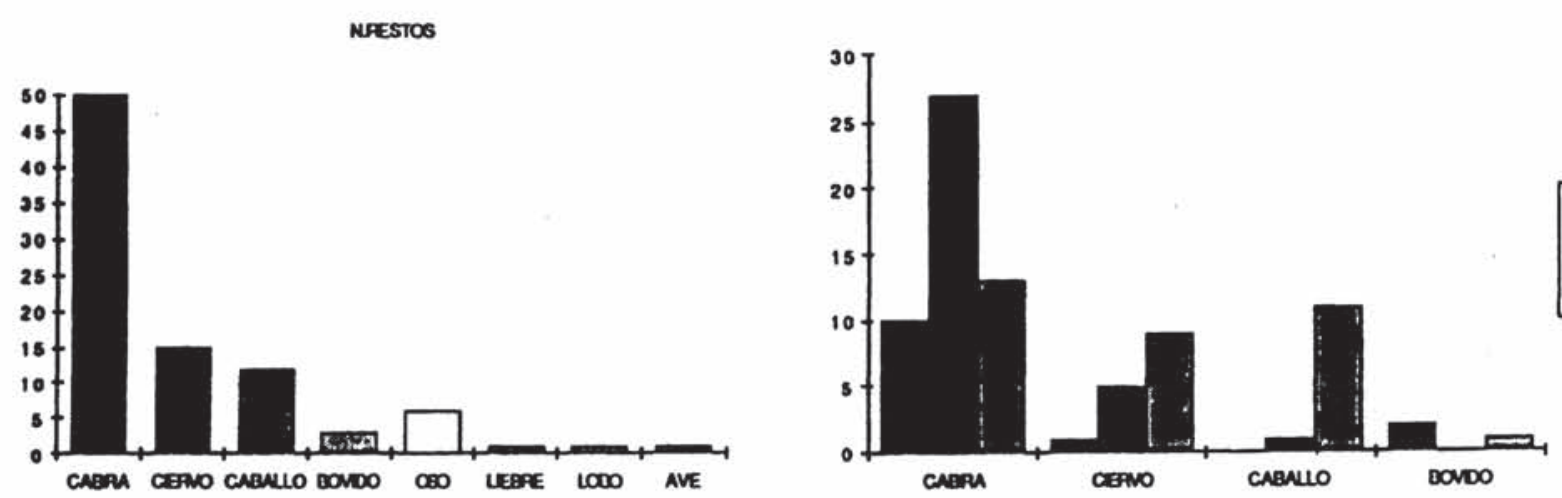

Fig. 5.- Gráficos del número de restos por especies y partes del cuerpo representados entre los restos paleontológicos del área de decoración de la cueva de Tito Bustillo. 


\begin{tabular}{|l|r|}
\hline ESPECIES: & N.RESTOS \\
\hline CABAA & 50 \\
\hline CFANO & 15 \\
\hline CABNLO & 12 \\
\hline BONDO & 3 \\
\hline OBO & 6 \\
\hline UEBRE & 1 \\
\hline LOBO & 1 \\
\hline AVE & 1 \\
\hline TOTAL & 89 \\
\hline
\end{tabular}

TB84/FAUNA

\begin{tabular}{|l|r|r|r|r|}
\hline A & B & \multicolumn{1}{c|}{ C } & \multicolumn{1}{c|}{ D } & \multicolumn{1}{c|}{ E } \\
\hline ESPECIES: & CABEZA & TRONO & EXTREM & TOTALES \\
\hline CABPA & 10 & 27 & 13 & 50 \\
\hline CERVO & 1 & 5 & 9 & 15 \\
\hline CABAULO & 0 & 1 & 11 & 12 \\
\hline BOVDO & 2 & 0 & 1 & 3 \\
\hline OBD & 0 & 0 & 6 & 6 \\
\hline UEBRE & 0 & 0 & 1 & 1 \\
\hline LOBO & 0 & 0 & 1 & 1 \\
\hline AVE & 0 & 0 & 1 & 1 \\
\hline
\end{tabular}

Fig. 6.- Nümero de restos por especies y partes del cuerpo representadas en el área de decoración de la cueva de Tito Bustillo.

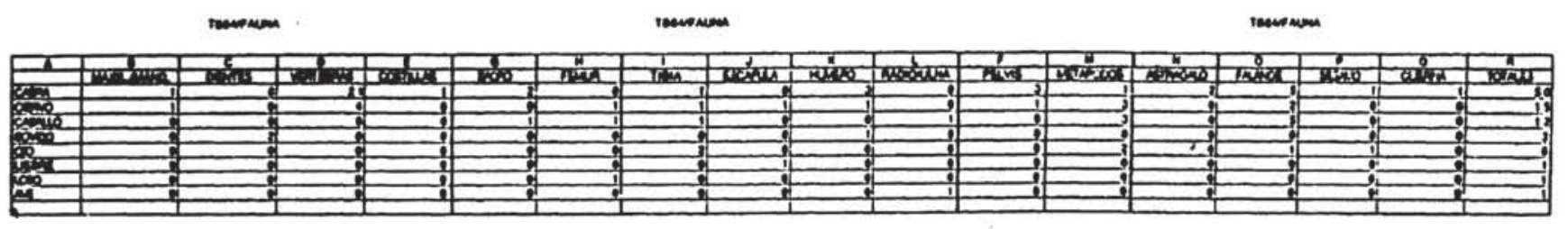

FIG. 7.- Relación entre restos y especies en el área de decoración de la cueva de Tito Bustillo.

En principio, el conjunto de las piezas no desentonaría en ninguna de las capas de la estratigrafía del área de asentamiento. Algunos elementos más singulares, como los fragmentos de plaquetas -obviamente de origen alóctono- o determinados elementos decorativos (varilla semicilíndrica, colgantes sobre Trivia) también tienen su paralelo en los dos complejos señalados en el yacimiento de la antigua entrada.

Las dataciones absolutas también aquí producen cierto desconcierto. Mientras que la datación CSIC 80 obtenida a partir de carbón vegetal proporcionó una fecha similar a las obtenidas en la entrada con el mismo tipo de material (14.350 $\pm 300 \mathrm{BP}$ ) la referenciada como Ly 3476 , conseguida durante nuestros trabajos de 1984 sobre una muestra de fragmentos óseos con escaso contenido de material orgánico, dió como resultado $12.890 \pm 530 \mathrm{BP}$. Las pruebas paleomagnéticas efectuadas por Kopper han sido dadas a conocer con dos resultados distintos en otras tantas publicaciones científicas, lo que desde luego no ayuda a inspirar demasiada confianza.

Puede ser significativa la coincidencia de las dataciones sobre carbón vegetal en ambas zonas de la cueva, que tal vez permitiría apoyar la idea de contemporaneidad, por otra parte bastante 
razonable si valoramos el resto de los datos mencionados y admitimos la idea de que los autores de las pinturas y grabados son los mismos ocupantes de la cueva. En nuestra opinión, tanto los vestigios del área de decoración como la serie del nivel 1 de la entrada encajan perfectamente en un episodio inicial del Magdaleniense Superior. Como en otros yacimientos cantábricos, sus respuestas tecnológicas y, sobre todo, su arte mobiliar, parecen formar un contexto único con el llamado Magdaleniense Medio tipo La Viña, Las Caldas, etc. Este complejo Medio-Superior Inicial coincide en la zona cantábrica con el apogeo del arte mueble y parietal, con una serie de caracteres y convenciones propios y la presencia del reno de forma más que esporádica entre los temas representados (Moure Romanillo, 1988).

\section{CONSIDERACIONES FINALES}

1. Durante los últimos años varios autores han señalado la importancia dentro de los espacios subterráneos con arte parietal, de vestigios de presencia y actividades humanas diferentes a los de los lugares de ocupación tradicionalmente valorados. Los espacios de tránsito o de decoración implican, además, cuestiones de conservación no muy diferentes a las estrictamente relacionadas con el arte paleolítico, y que, en último extremo, se refieren a la necesidad de preservar el espacio subterráneo, y conservar las condiciones que han permitido que sus manifestaciones artísticas hayan llegado hasta nosotros.

No obstante, los vestigios de desplazamiento, acceso, referencias topográficas, etc., son más fácilmente destruibles, incluso de manera no intencional, como consecuencia de exploraciones espeleológicas no controladas o poco rigurosas, y -sobre todo- de obras de acondicionamiento destinadas a facilitar la explotación turística de las cuevas. El trabajo presentado intenta una aproximación al empleo del medio subterráneo y a las técnicas utilizadas por parte de los artistas paleolíticos, ejemplificado con las experiencias recientemente realizadas por nosotros en la cueva de Tito Bustillo (Asturias, España), en que ha sido posible estudiar y relacionar un área de asentamiento situada en una zona de luz de día y penumbra con un área de decoración ubicada en un tramo profundo de la cueva.

2. El estudio de los vestigios situados en las áreas de decoración comporta el análisis de restos o estructuras representativas de los procedimientos de acceso a los paneles, ejecución de las pinturas, grabados o esculturas, iluminación y subsistencia. Los ejemplos de Lascaux, Tête-du-Lion y Tito Bustillo pueden ser especialmente ilustrativos e incluso complementarios, dada la ausencia de área de asentamiento en las cuevas francesas.

3. El estudio preliminar del área de decoración de la cueva de Tito Bustillo se ha orientado en primer lugar a rescatar y revisar el material y las estructuras dejados in situ en los trabajos de 1970. Ello ha permitido identificar, al menos, una estructura de tipo hogar, documentar la distribución actual de los restos, iniciar el estudio funcional del material lítico, llevar a cabo análisis de colorantes, obtener una nueva datación absoluta por $\mathrm{C} 14$, y clasificar los restos paleontológicos. No obstante, no hay que pasar por alto que posiblemente nos encontremos ante una muestra parcial de una superficie más amplia hoy destruida.

4. La industria lítica del área de decoración de Tito Bustillo constituye una muestra ciertamente escasa, pero de la que pueden extraerse algunos datos significativos. En primer lugar, sorprende la repartición por materias primas: la cuarcita se encuentra en torno al hogar, mientras que el sílex es predominante en el resto de la superficie explorada. Entre los restos de talla destacan los golpes de reavivado de buril, que a su vez se agrupan debajo del área decorada, mientras que tan sólo hay un ejemplar junto al hogar. El número de útiles es reducido, pero 15 de 19 son buriles, clasificación que contrasta ampliamente con la realizada durante los primeros sondeos. El estudio de microhuellas de uso en los restos de talla clasificados como golpes de buril indica la presencia de vestigios de material colorante (Láms. II, 1 y III, 1 y 2). 
5. En lo que concierne a los restos faunísticos, y siempre a partir de la muestra conservada y, dentro de ella, de los restos determinables, parece deducirse una selección de animales y de restos diferente a la del área de asentamiento. Predomina la cabra, especie cuya presencia es importante en el yacimiento de la entrada, pero que se encuentra lejos de ser la primera tanto en número de restos como de individuos. Junto a los cápridos aparece el ciervo, el gran bóvido, caballo, oso y lobo, si bien -sobre todo los dos últimos- en proporciones mínimas. En cuanto a selección de partes del cuerpo, los restos de animales de gran talla consisten en extremidades pertenecientes a varios individuos. En el caso de las cabras aparecen huesos de patas, vértebras correspondientes a varios tramos de la columna y maxilares. La selección de partes del cuerpo y la fragmentación de los huesos largos indica, sin lugar a dudas, su empleo como alimento.

6. La presencia de algunos objetos de arte mueble o de adorno sólo hemos podido interpretarla como indicativa de pérdida: tres colgantes, una varilla decorada y un fragmento de placa grabada. En los tres casos los colgantes son conchas de Trivia europea con sendas perforaciones, obtenidas por percusión, en cada extremo. Este tipo de adorno se encuentra bastante representado en las distintas capas del Magdaleniense Superior del yacimiento de la entrada: 28 ejemplares en el complejo superior (capas 1a a 1c.1) y 15 en el inferior (capas 1c.2 a 1c.4).

La varilla es una pieza semicilindrica de base en doble bisel oblicuo. La cara dorsal presenta decoración con motivos de aspas y reverso cubierto de incisiones oblicuas. El tipo de soporte está representado en los dos complejos, superior e inferior del yacimiento de la entrada en cantidades absolutas y relativas muy semejantes. En el primero hay incluso cuatro piezas con la misma decoración ventral. El motivo de aspas es menos frecuente; se produce literalmente en una varilla de la capa 1c.2, dos azagayas de bisel simple, una de $1 \mathrm{~b}$ y otra del nivel 2, y existen formas próximas (líneas en zig-zag, trazos convergentes, etc.), en toda la estratigrafía. La placa arenisca también citada presenta líneas indeterminables como las que aparecen, asociadas a otros fragmentos, con o sin figuraciones, en el complejo superior del área de estancia.

7. Las dataciones absolutas presentan contradicciones internas, aunque encajan en el también problemático marco que nos presentan las fechas del área de asentamiento. Aunque arqueológicamente sea indeterminable por los elementos que contiene, en nuestra opinión su correspondencia con el nivel 1 del yacimiento de la entrada y, desde luego, con las pinturas y grabados del conjunto $\mathrm{X}$, es perfectamente defendible.

8. Finalmente, insistir en el carácter parcial de los vestigios del área de decoración, que posiblemente se hayan visto disminuidos como consecuencia tanto de procesos naturales como por la intervención humana. Nuestro propósito para el futuro es continuar los trabajos tanto en el área de estancia como en el de decoración. En esta última se intentará la ampliación del área excavada para la eventual localización de zonas intactas coincidentes con otros paneles de la sala. En caso de que las excavaciones diesen un resultado positivo, el trabajo continuaría en las líneas antes iniciadas: estudio funcional del material lítico, análisis de colorantes, interpretación de los restos faunísticos, dataciones absolutas, etc. En todo caso, y a pesar de las circunstancias que dieron lugar a la localización de este pequeño depósito al pie del panel principal, no cabe duda del extraordinario interés de la cueva de Tito Bustillo y de la cantidad de información que aún puede proporcionar, tanto respecto a su arte parietal como a otros testimonios de la presencia y actividad humana. 


\section{BIBLIOGRAFIA}

AlCalde del Rfo, H. (1906): «Exploration au gisement d'Altamiran. En Cartailhac, E. y Breuil, H.: La Caverne d'Altamire a Santillane près Santander (Espagne). Monaco. Imprimerie de Mónaco: 257-275.

ALLaw, J. (1965): «Les Lampes magdaléniennes de Saint-Marcel (Indre)», Congrès Préhistorique de la France. XVI session (Monaco, 1959): 178-183.

- (1979): "L'Industrie lithique et osseuse de Lascaux", en Arl. Lerol-Gourhan y Allain, J.: Lascaux inconnu, CNRS, París: 87-119.

Almagro Basch, M. (1976): «Los omóplatos grabados de la cueva de "El Castillo", Puente Viesgo (Santander)». Trabajos de Prehistoria, 33: 9-112.

Almagro Basch, M.; Garcta Guinea, M. A.; Berenguer Alonso, M. (1973): «La época de las pinturas y esculturas cuaternarias policromas en relación con los yacimientos: revalorización del Magdaleniense IIIn. Santander Symposium. UISPP, Madrid: 467-474.

Almagro Gorben, M. (1974): «C-14, 1974. Cincuenta nuevas fechas para la Prehistoria y la Arqueología Penínsularesw. Trabajos de Prehistoria, 31: 229-294.

AltuNA, J. (1976): «Los mamíferos del yacimiento prehistórico de Tito Bustillo (Asturias), en pp. 151-194 de Moure Romanilo, J. A. y Cano Herrera, M.: Excavaciones en la cueva de Tito Bustillo (Asturias), Instituto de Estudios Asturianos, Oviedo.

Altuna, J.; Baldé́n, A.; Mariezkurrenu, K. (1984): «Dépots rituels magdaleniens de la grotte d'Erralla (Pays Basque)m. Munibe, 36, 3-4: 3-10.

Balbin BehrmanN, R. DE; Moure Romanilo, J. A. (1980a): «Pinturas y grabados de la cueva de Tito Bustillo (Asturias): El conjunto In. Trabajos de Prehistoria, 37: 365-382.

- (1980b): «La "Galería de los Caballos" de la cueva de Tito Bustillow Altamira Symposium, Ministerio de Cultura, Madrid: 85-118.

- (1981): «Las pinturas y grabados de la cueva de Tito Bustillo. El sector orientab. Universidad de Valladolid. Studia Archaeologica, 66. Valladolid.

- (1982a): «El panel principal de la cueva de Tito Bustillo (Ribadesella, Asturias)». Ars Praehistorica, 1: 47-97.

- (1982b): «Plan de investigación en la cueva de Tito Bustillow. Revista de Arqueología, 15: 36-45.

- (1983): «Las superposiciones en el panel principal de la cueva de Tito Bustillo. Homenaje al Prof. D. Martín Almagro Basch, I, Ministerio de Cultura, Madrid: 289-300.

Barandiarán Maestu, I. (1967): El paleomesolítico del Pirineo Occidental Bases para una sistematización del material óseo paleolitico. Universidad de Zaragoza. Zaragoza.

- (1984): «Utilización del espacio y proceso gráfico en el arte mueble paleolítico». Scripta Praehistorica. Universidad de Salamanca. Salamanca: 113-162.

BeAUNE-RomerA, S. DE (1984): «Comment s'eclairaient les hommes prehistoriques». La Recherche, 152: $247-249$.

- (1987a): «Palaeolithic lamps and their specialization: a hypothesis». Current Anthropology, 28-4: 569-577.

- (1987b): Lampes et godets au Paléolithique, XXIII Supplement à Gallia Préhistoire. Paris.

Benune-RomerA, S. DE; Roussot, A. (1983): «Les lampes de Saint-Germain-La Riviére (Gironde)», Revue Historique et Archaeologique du Libournais, 50-185: 101-109.

Begouen, H.; BReUIL, H. (1958): Les cavernes du Volp. Trois Frères-Tuc d'Audoubert à Montesquieu-Avantes (Ariege. Travaux de l'Institut de Paleonlogie Humaine. Paris.

Begouen, R.; Clottes, J. (1983): «El arte mobiliar de las cavernas del Volp (en Montesquieu-Avantès) (Ariège). Revista de Arqueología, 27: 6-17.

Bernaldo de QUIRÓS, F.; Moure Romanillo, J. A. (1978): «Cronología del paleolítico y Epipaleolítico peninsulares». En C-14 y Prehistoria de la Península Ibérica. Fundación Juan March (Serie Universitaria 77). Madrid: 17-35.

BOsInsKI, G.; Fischer, G. (1973) «Die Menscheendarstellungen von Gonnersdorf der Ausgrabung von 1968». Der Magdalenien-Fundplatz Gonnersdorf I. Franz Steiner Verlag, Eüsbaden.

Breull. H.; Obermaier, H.; Alcalde del Rio, H. (1913): «La Pasiega a Puente Viesgo (Santander). Mónaco.

BreuIl. H.; Obermaier, H. (1935): The Cave of Altamira at Santillana del Mar Spain. Junta de las Cuevas de Altamira. The Hispanic Society y Academia de la Historia, de Madrid.

Cabrera Garrido, J. M. (1978): «Les materiaux de peinture de la Caverne d'Altamiran. Comite de l'ICROM pour la Conservation. Zagreb.

Cabrera Valdes, V.; Bernaldo de Quiró, F. (1981): «Primeros resultados de la investigación en la Cueva del Salitre (Santander)w. Altamira Symposium. Ministerio de Cultura. Madrid: 141-156.

CAMPS, G. (1972): «Art paleolíthique et manifestation de la personnalitéw. Santander Symposium. UISPP. Madrid: 139-146.

ClotTes, J.; Begouen, C. DE (1981): «Apports mobiliers dans les cavernes du Volp (Enlène. Les Trois Frères, Le Tuc d'Audoubert)w. Altamira Symposium. Ministerio de Cultura. Madrid: 157-188.

COMBIER, J. (1984): «Grottes ornées d'Ardèche», en pp. 80-86 de Les premiers artistes, derniers chasseurs de la Préhistoire. Histoire et Archeologie. Les Dossiers. 87. 
Couraud, C.; Laming.Emperaire, A. (1979): «Les colorants», en Arl. Leroi-Gourhan, y Allain, J.: Lascaux inconnu. CNRS, Paris: 153-170.

DejBe BAlbas, M. A. (1985): Los colgantes magdalenienses de la cueva de Tito Bustillo. Memoria inédita. Departamento de Prehistoria y Arqueología de la Universidad de Cantabria. Santander.

Delluc, B y G. (1979): «L'Eclairage» en LeRoI-Gourhan, Arl. y Allain J., Lascaux inconnu. CNRS. París: 121-143.

DELPORT, H.; MONS, L. (1977): «Principes d'un ètude sur les supports osseux de l'art paléolithique mobilien. Colloque 568 du CNRS: Methodologie aplliquée a l'Industrie de l'os prèhistorique (Abbaye de Senanque, 1976). CNRS, París: 69-76.

Garcin Guine^, M. A. (1975): Primeros sondeos estratigráficos en la cueva de Tito Bustillo (Ribadesella, Asturias). Excavaciones en 1970. Patronato de las Cuevas Prehistóricas de la Provincia de Santander. Santander.

GloRY, A. (1958): «Rapport Géneral résumé de la mission à la Grotte de Lascaux du 13 décember 1957 au 7 fevrier 1958 el du 10 mars au 15 avril 1958w. (Tomado de Couraud, C. y LAming-EMPERAIRE, A., 1979: 158).

González Echegaray, J.; Barandiarán Maestu, I. (1981): «El Paleolitico Superior de la cueva de Rascaño (Santander). Centro de Investigaciones y Museo de Altamira (monografía $n^{2} 3$ ). (Santander).

Gonzílez Echegaray, J.; Freeman, L. G. (1981): «Máscara del Santuario de la cueva del Juyo» Altamira Symposium. Ministerio de Cultura. Madrid: 251-266.

González Morales, M. R.; Moure Romanillo J. A (1984): «Las cuevas de Monte Castillo. Un conjunto prehistórico excepcionalw. Revista de Arqueología. 41: 30-40.

GoNZÁlEZ SAINZ, C. (1984): «Sobre la plaqueta grabada magdaleniense de la cueva de Urtiaga (Guipúzcoa)». Munibe. 36: 11-17.

KOPPER, S. (1973): «Datación paleomagnética de las pinturas del Paleolítico Superior de la cueva de Tito Bustillo, Asturias (España)». Trabajos de Prehistoria. 30: 319-323.

KOPPER, S.; CREer, K. M. (1974): «Paleomagnetic Datting of cave painting in Tito Bustillo cave, Asturias, Spain». Science. 186: 348-350.

LAMING.EMPERAIRE, A. (1964): Lascaux: peintures et gravures. U.G.E. París.

Leroi-Gourhan, A. (1971): Prehistorie de l'Art Occidental Mazenod. París.

MARTí, J. (1977): Informe sobre los estudios realizados en las cuevas de Altamira. Instituto de Catálisis y Petroquímico del C.S.I.C. Madrid. Inédito.

Mons, L. (1972): «Notes de technologie de l'Art Paleolithique». Antiquités Nationales. 4: 14-21.

Moure Romanillo, J. A. (1974): «Bastón de mando descubierto en el Magdaleniense Superior de Tito Bustillo (Ribadesella, Asturias)». Boletín del I.D.E.A., 83: 842-853.

- (1975): Excavaciones en la cueva de «Tito Bustillo (Asturias): campañas de 1972 y 1974. Instituto de Estudios Asturianos. Oviedo.

- (1979): «Le Magdalenien Supérieur de la Grotte de Tito Bustillo (Asturias, Espagne)». Colloque n. 271 CNRS. «La fin des temps glaciaires en Europe* (Tallence 24-28 mai 1977). CNRS. París: 737-743.

- (1980): Las pinturas y grabados de la cueva de Tito Bustillo: significado cronológico de las representaciones de animales. Universidad de Valladolid. Studia Archaeologica, 61. Valladolid.

- (1982a): «Espátula decorada del Magdaleniense de la cueva de Tito Bustillow. Boletín del Instituto de Estudios Asturianos. 107: 667-681.

- (1982b): Placas grabadas de la cueva de Tito Bustillo. Universidad de Valladolid, Studia Archaeologica, 69. Valladolid.

- (1983): «Escultura magdaleniense descubierta en la cueva de Tito Bustillow. Ars Praehistorica. 2: 169-176.

- (1984): «Representaciones femeninas en el arte mueble de la cueva de Tito Bustillon. Boletín del Museo Arqueológico Nacional. II: 69-76.

- (1985): «El Paleolítico y el Arte Rupestre en Burgos». Historia de Burgos I. Caja de Ahorros Municipal de Burgos. Burgos: 85-114.

- (1988): «Relations entre l'art rupestre et l'art mobilier dans la Region Cantabriquen. Colloque Internacional d'Art Mobilier Paleolithique (Foix-Le Mas d'Azil, nov. 1987) (En prensa).

- Cano Herrera. M. (1976): Excavaciones en la cueva de Tito Bustillo (Asturias): trabajos de 1975. Instituto de Estudios Asturianos. Oviedo.

- (1978): *Magdalenian habitation estructure at Tito Bustillo cave (Asturias, Spain). Current Anthropology, 19.2: 392-394.

- (1979): «Tito Bustillo cave (Asturias, Spain) and the Magdalenian of Cantrabria». World Archaeology, 10,3: 280289.

NewCOMer. M. (1977): «Experiments in Upper paleolithic bone workw. Colloque 568 du CNRS. Methodologie appliquée a l'industrie de l'os prehistorique. (Abbaye de Senanque, 1976). CNRS, Parí: 292-301.

OBermaIER, H. (1925): El hombre fósil. Comisión de investigaciones Prehistóricas y Protohistóricas. Madrid.

Ortega Mateos, L. (1983): «Huellas humanas en una cueva de la Provincia de Palencia». Revista de Arqueología. 24: 42.

PerLes, C. (1977): Prehistoire du feu. Masson et Cie. París.

PIETSCH. E (1964): *Altamira y la Prehistoria de la Tecnología Químicas. Patronato de Investigaciones Científicas y Técnicas «uan de la Cierva* (CSIC). Madrid. 
Rigaud, J. PH. (1970): «Etude preliminaire des industries magdalenienses de l'abri du Flageolet II, comune de Bézenon (Dordogne)», BSPF, 67.

Roussot, A.; BEAUNE-ROMERA, S. DE (1982): «Quelques lampes paleolithiques peu connues du Sud-Ouest de la Francen. BSPF, 79, 10-12: 369-382.

Rouzaud F. (1978): La Paleospeleologie. L'Homme et le milieu souterrain pyrénnéen au Paléolithique Supérieur. Archives d'Ecologie Prehistorique. Toulouse.

Sanz de Sautuola, M. (1980): Breves apuntes sobre algunos objetos prehistóricos de la Provincia de Santander. Santander.

San Juan Dinz, C. (1985): El uso de ocre y otros colorantes en el Paleolitico Superior de Cantabria. Memoria inédita. Dpto. de Prehistoria y Arqueologia de la Universidad de Cantabria. Santander.

UribarRI J. L.; Llz, C. (1973): «El arte rupestre de Ojo Guareña. La cueva de Kaite». Trabajos de Prehistoria, 30: $69-120$. 

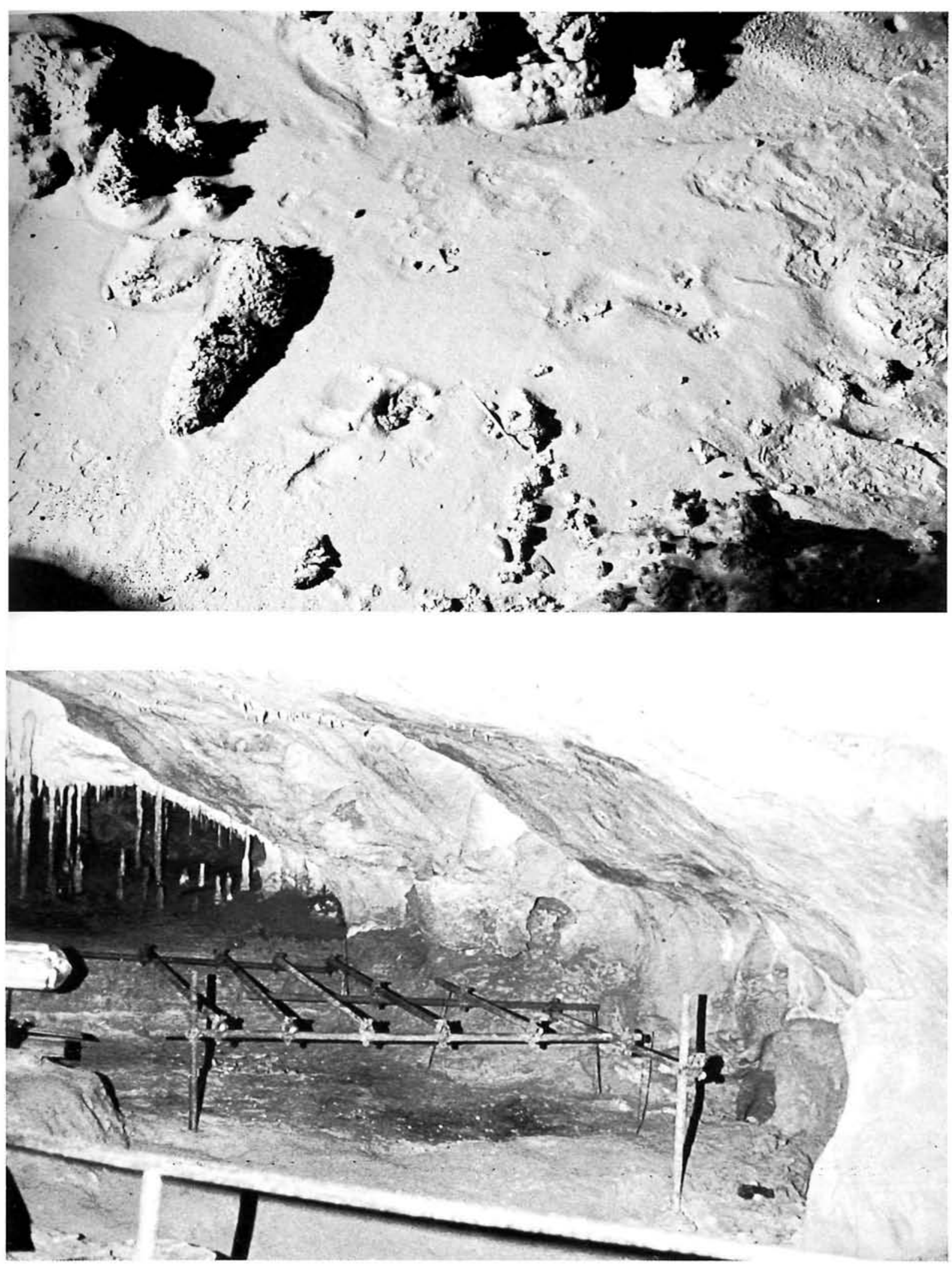

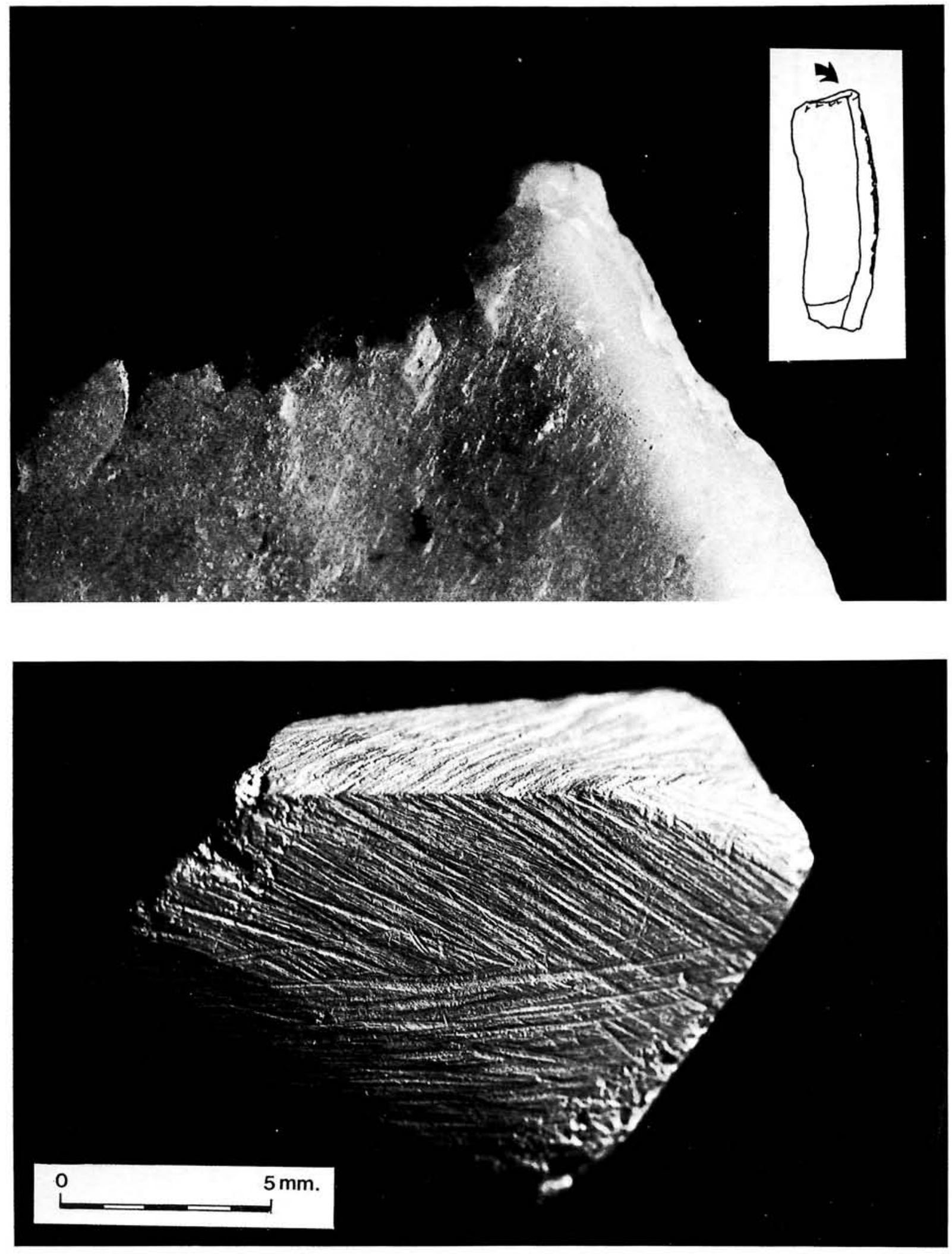

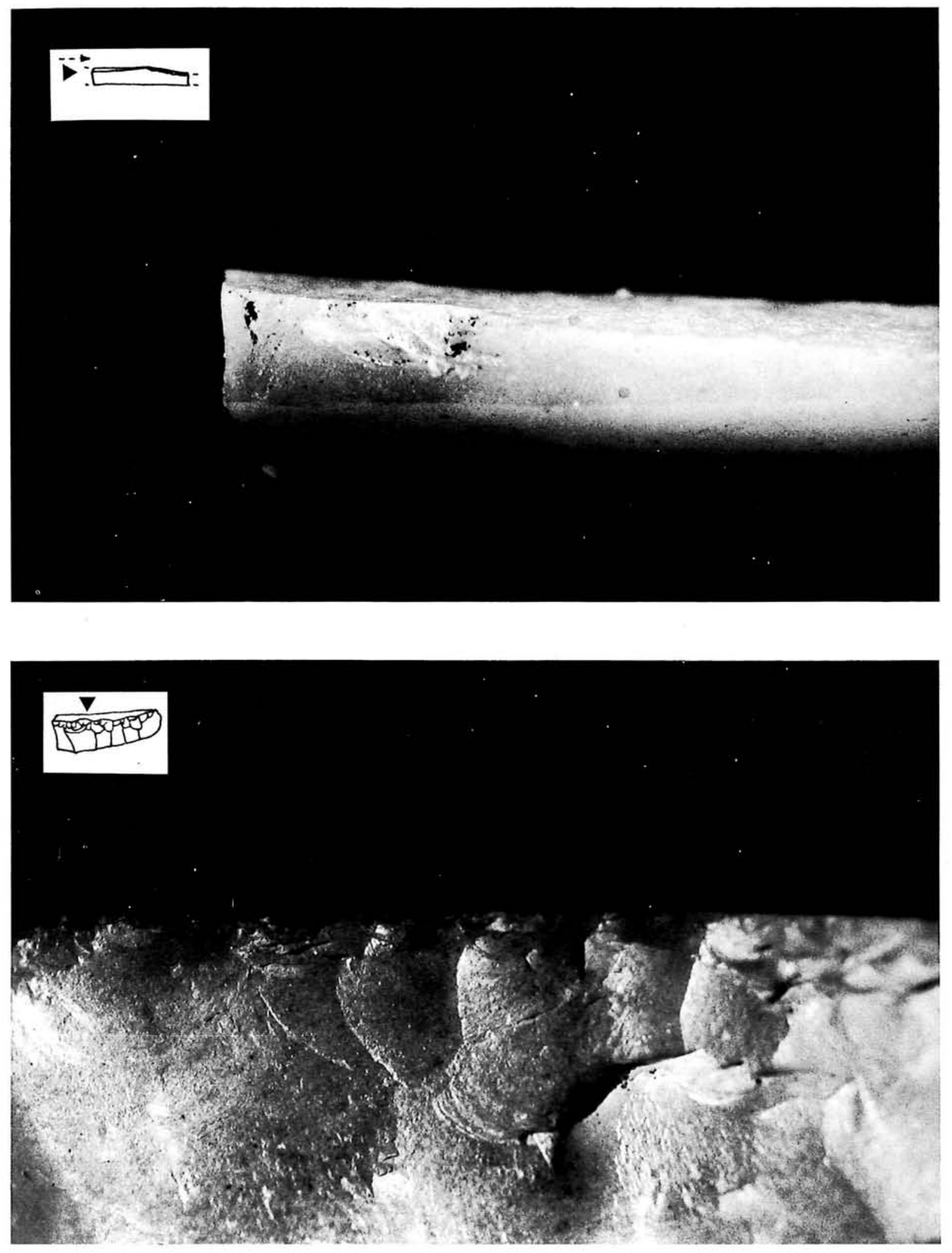